TITLE:

\title{
SPHINGOSINE 1-PHOSPHATE MEDIATES ADIPONECTIN RECEPTOR SIGNALING ESSENTIAL FOR LIPID HOMEOSTASIS AND EMBRYOGENESIS
}

RUNNING TITTLE: S1P promotes membrane homeostasis

AUTHORS: Mario Ruiz ${ }^{1 * 4}$, Ranjan Devkota ${ }^{1}$, Dimitra Panagaki ${ }^{1}$, Per-Olof Bergh ${ }^{2}$, Delaney Kaper $^{1}$, Marcus Henricsson ${ }^{2}$, Ali Nik ${ }^{1}$, Kasparas Petkevicius ${ }^{3}$, Johanna L. Höög ${ }^{1}$, Mohammad Bohlooly-Y ${ }^{3}$, Peter Carlsson ${ }^{1}$, Jan Borén ${ }^{2}$, Marc Pilon $^{1}$

\section{AFFILIATIONS:}

${ }^{1}$ Dept.Chemistry and Molecular Biology, Univ. Gothenburg, 40530 Gothenburg, Sweden, ${ }^{2}$ Dept. Molecular and Clinical Medicine/Wallenberg Laboratory, Institute of Medicine, Univ. of Gothenburg, 41467 Gothenburg, Sweden, ${ }^{3}$ Discovery Biology, Discovery Sciences, R\&D, AstraZeneca, Gothenburg, Sweden. ${ }^{4}$ Lead Contact.

CORRESPONDING TO: * Mario Ruiz (mario.ruiz.garcia@gu.se) or Marc Pilon (marc.pilon@cmb.gu.se), Dept. Chem Mol Biol, Univ. Gothenburg, Box 462, Gothenburg, SE-405 30, Sweden. Tel: +46 317863279. 


\section{Graphical Abstract}

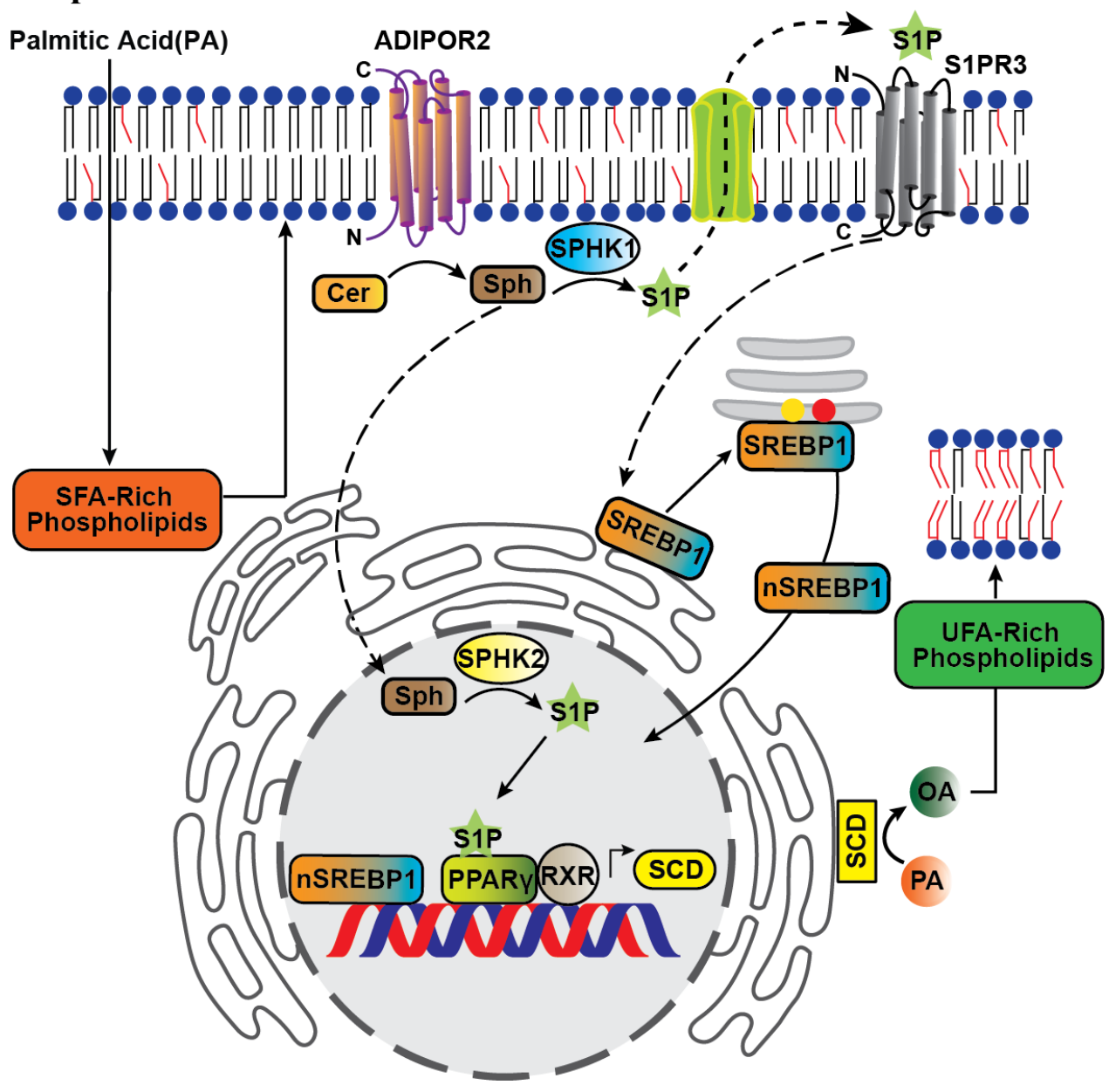

\section{In Brief}

Cells and organisms require proper membrane composition to function and develop. Ruiz et al. identified AdipoR1/2-derived S1P as essential for membrane homeostasis in mammals and invertebrates. S1P signals through SREBP and PPAR $\gamma$ to sustain fatty acid desaturation. Targeting AdipoR1/2 pathway may be a therapeutic approach for disorders with dysfunctional membranes.

\section{Highlights}

- Excess membrane phospholipid saturation explains AdipoR1/2 DKO embryonic lethality

- AdipoR1/2 DKO membrane defects are rescued by S1P

- Parallel activation of S1PR3 and PPAR $\gamma$ by S1P mediates AdipoR2 membrane protection

- Fatty acid desaturation is the final outputs of the AdipoR2-S1P signaling pathway 


\section{Summary}

Cells and organisms require proper membrane composition to function and develop. Phospholipids are the major component of membranes and are primarily acquired through the diet. Given great variability in diet composition, cells must be able to deploy mechanisms that correct deviations from optimal membrane composition and properties. Here, using unbiased lipidomics and proteomics, we found that the embryonic lethality in mice lacking the fluidity regulators Adiponectin Receptors 1 and 2 (AdipoR1/2) is associated with aberrant high saturation of the membrane phospholipids. Using mouse embryonic fibroblasts (MEFs) derived from AdipoR1/2-KO embryos, human cell lines and the model organism C. elegans we found that, mechanistically, AdipoR1/2-derived sphingosine 1-phosphate (S1P) signals in parallel through S1PR3-SREBP1 and PPAR $\gamma$ to sustain the expression of the fatty acid desaturase SCD and maintain membrane properties. Thus, our work identifies an evolutionary conserved pathway by which cells and organism maintain membrane homeostasis and adapt to a variable environment.

\section{Keywords:}

Adiponectin Receptor, Embryonic Lethal, Sphingosine 1-phosphate, Laurdan, SREBP, PPARG, SCD, Membrane Fluidity, Phospholipid, Palmitic acid. 


\section{INTRODUCTION}

Lipid membranes function as barriers that not only delimit cell boundaries, but also define internal compartments within eukaryotic cells. Approximately one third of all proteins are integral membrane proteins (Krogh et al., 2001) and many more are membrane-associated proteins. Therefore, multiple cellular processes occur at or in connection with membranes. Perturbations in membrane composition and properties can have dramatic consequences for the cell/organism. For instance, lipotoxicity can often be explained by excessive membranelipid packing that in turn can be caused by a diet rich in saturated fats or by the loss of membrane regulators such as the Adiponectin Receptors (AdipoR1 and AdipoR2) (Devkota et al., 2021a; Piccolis et al., 2019; Ruiz et al., 2021; Zhu et al., 2019).

The AdipoR1/2 proteins are often discussed in the context of diabetes due to their ability to promote insulin sensitivity and oppose hepatic steatosis (Holland et al., 2017; Iwabu et al., 2021; Yamauchi et al., 2007). AdipoR1 and AdipoR2 single knockout mice are viable but the simultaneous ablation of both AdipoRs (DKO) causes embryonic lethality (Lindgren et al., 2013), though the primary cause of death has not been investigated. Studies in mammalian cells of different origin and in the nematode $C$. elegans have shown that a primary and evolutionary conserved function of the AdipoR $1 / 2$ proteins is to promote the expression of fatty acid desaturases to maintain membrane homeostasis (Pilon, 2021; Ruiz et al., 2019; Svensk et al., 2013). In particular, an RNAseq study highlighted that stearoyl-CoA desaturase $(S C D)$ was the most robustly downregulated gene in cells lacking AdipoR2 (Ruiz et al., 2021). At the molecular level, AdipoR1/2 possess an intrinsic ceramidase activity that catalyzes the hydrolysis of ceramides to produce sphingosine and free fatty acids (Vasiliauskaite-Brooks et al., 2017). The resulting sphingosine can be phosphorylated by sphingosine kinases 1 and 2 (Sphk1/2) to produce the signaling molecule sphingosine 1-phosphate (S1P) and, speculatively, mediate AdipoR1/2 function (Green et al., 2021; Holland et al., 2011; Onodera et al., 2021).

S1P is an essential (Mizugishi et al., 2005) and bioactive lipid involved in several cellular and physiological processes including cell survival, migration, inflammation and development (Mendelson et al., 2014; Ruiz et al., 2017a; Ruiz et al., 2017b). S1P can be exported out of the cells and signal through a family of G-protein-coupled receptors, GPCRs (S1P receptors 1-5, S1PR1-5) (Blaho and Hla, 2014). Alternatively, S1P can also bind to several intracellular targets such as the peroxisome-proliferator activated receptor $\gamma$ (PPAR $\gamma$ ) and the histone deacetylases 1 and $2(\mathrm{HDAC} 1 / 2)$ to modulate the transcriptional response of the cell (Hait et al., 2009; Parham et al., 2015).

Here, to better understand the cause of AdipoR1/2 embryonal lethality, we generated DKO mouse embryos and examined their tissue structure, lipidome and proteome. We found that the membranes of mouse embryos lacking both AdipoRs are mostly composed of phospholipid containing saturated fatty acids. Furthermore, we investigated the pathway behind AdipoR1/2mediated membrane regulation. Of particular interest, we discovered that AdipoR1/2 derived S1P mediates membrane homeostasis by activating in parallel 1) the sterol regulatory elementbinding protein-1 (SREBP1) via S1PR3; and 2) PPAR $\gamma$. Both transcription factors are wellknown master regulators of lipid metabolism and here we show that they are regulated by AdipoR1/2-derived S1P to sustain the expression of the fatty acid desaturase SCD that in turn modulates membrane properties. 


\section{RESULTS}

\section{AdipoR1/2 DKO Embryonic Lethality is Associated with Excess Membrane Phospholipid Saturation}

Deficiency of both AdipoR1 and AdipoR2 leads to embryonic lethality in mice (Lindgren et al., 2013), but the underlying cause is not well understood. The recent emergence of AdipoR1/2 as regulators of membrane composition and fluidity (Pilon, 2021) suggests that membrane composition defects could contribute to the DKO embryonic lethality. To test this hypothesis, we first crossed AdipoR1/2 double heterozygous with each other mice and collected E12.5 and E15.5 embryos (Figure 1A). A single DKO embryo was found at E15.5 and showed obvious morphological defects, drastic reduction in size and was pale in color (Figure 1A and Table S1). The extremely low frequency of DKO embryos isolated is noteworthy: we expected to find one DKO embryo out of every sixteen embryos (mendelian ratio), but instead found only one in forty-six. In contrast, we recovered the expected proportion of DKO embryos at E12.5 (Figure 1A and Table S1), indicating that DKO embryos are formed, but failed and were resorbed between the E12.5 and E15.5 stages. To gain insight into the causes of AdipoR1/2 embryonic lethality, we performed histology, lipidomics and proteomics of E12.5 embryos (Figure 1B). Histology of E12.5 wild-type (WT) and DKO embryos did not reveal any major morphological defects in the DKO embryos (Figure 1C and S1A-H) suggesting that morphological defects are preceded by molecular changes.

Lipidomics analysis of the membrane phospholipids phosphatidylcholine (PC) and phosphatidylethanolamine (PE), triacylglycerols (TAG), free cholesterol (FC) and the sphingolipids sphingomyelin (SM), ceramide (Cer), dihydroceramide (DiCer), glucosylceramide (GluCer) and lactosylceramide (LacCer) allowed for a clear separation of WT, AdipoR1-KO, AdipoR2-KO and DKO E12.5 embryos in a principal component analysis (PCA) (Figure 1D). The PCA further revealed that most of the separation between genotypes (PC1 accounted for $78 \%$ of the variance) is explained by differences in the abundance of palmitic acid (PA, 16:0) in membrane phospholipids (Figure S1I). A volcano plot comparing WT and DKO embryos revealed significant changes in 56 lipid species/classes, most of them being phospholipids (Figure 1E). PC and PE species containing saturated fatty acids (SFA), especially PA, were strikingly over-represented in DKO embryos whereas monounsaturated fatty acids (MUFA; e.g., oleic acid (OA, 18:1) and palmitoleic (PalOA, 16:1)) and polyunsaturated fatty acids (PUFA; e.g., arachidonic acid (AA, 20:4)) were more abundant in the phospholipids of WT embryos (Figure 1E). Accordingly, a heat map of all four genotypes shows a clear gradient in phospholipid saturation: DKO $>$ AdipoR2-KO $>$ AdipoR1-KO $>$ WT (Figure $1 \mathrm{~F}$ and $\mathrm{S} 1 \mathrm{~J}-\mathrm{O}$ ). In contrast, we did not find any differences in the ratios between lipids classes, namely PE/PC, TAG/PC, FC/PC, SM/PC, Cer/PC, DiCer/PC, LacCer/PC or GluCer/PC (Figure S1P-T and Table S2). These results are consistent with AdipoR1/2 being essential proteins that sustain fatty acid desaturation to regulate membrane composition /fluidity. Moreover, the lipidomics analysis indicates a more prominent role for AdipoR2 over AdipoR1, which is consistent with previous studies human cells (Devkota et al., 2017; Ruiz et al., 2019). 
To further investigate the cause of the lethality of DKO embryos, we compared the proteomes of WT and DKO E12.5 embryos and identified 7093 proteins, including 266 that were mis-regulated in the mutant: 185 proteins were upregulated and 81 downregulated in DKO embryos (Figure $1 \mathrm{G}$ and Table S3). To find associations among the 266 misregulated proteins, we performed a gene set enrichment analysis (GSEA), which grouped 97 protein into 16 pathways (Figure 1H, S1V and Table S3). Proteins from multiple metabolic pathways, including glycerolipid metabolism and fatty acid metabolism (Figure 1I), were present at higher levels in the DKO embryos, as indicated by a positive enrichment score. In contrast, the "SNARE interactions in vesicular transport" pathway was the only one with a significant negative score based on protein abundance (Figure 1H, S1V and Table S3), which is again consistent with membrane defects in the DKO embryos.

AdipoR2 regulates cell membrane fluidity cell non-autonomously (Bodhicharla et al., 2018) and, interestingly, our proteomics analysis also revealed that the abundance of several apolipoproteins, that can mediate lipid transport between cells and tissues, was diminished in the DKO embryos. More specifically, Apolipoprotein A1 (ApoA1) and Apolipoprotein B100 (ApoB), which are the major components of high-density lipoproteins (HDL) and low-density lipoproteins (LDL) respectively, were reduced to $\sim 50 \%$ of the WT levels (Figure 1J). This result is consistent with poor lipid exchange between tissues (Bodhicharla et al., 2018). Similarly, the levels of Apolipoprotein E (ApoE) and Apolipoprotein M (ApoM) were also about half of WT levels (Figure 1J-K). ApoM is particularly interesting because its ligand, S1P, has been suggested to mediate AdipoR1/2 signaling (Holland et al., 2011).

Collectively, our results suggest that AdipoR1/2 DKO embryonic lethality is caused by metabolic problems that are likely a secondary consequence of membrane malfunction due to an excess of SFA-containing phospholipids.

\section{DKO MEFs Reproduce the Membrane Defects in DKO Embryos}

We next sought to decipher the precise mechanism by which AdipoR1/2 regulates phospholipid saturation and hence membrane homeostasis. For that, we moved to a more flexible experimental system and obtained mouse embryonic fibroblasts (MEFs) from WT, AdipoR1KO, AdipoR2-KO and DKO embryos at E12.5 (Figure 1B) and studied their membranes. DKO MEFs showed membrane composition defects similar to those observed in embryos, and the addition of PA to the culture exacerbated these defects. More specifically, DKO MEFs accumulated higher amounts of PA in PC and PE at the expense of OA and AA (Figures 2A$B$ and S2A-C and Table S4). Importantly, the supplementation of the MUFA OA partially corrected the defects caused by PA treatment (Figures 2A-B and S2A-B and Table S4). As in embryos, phospholipids in DKO MEFs were more saturated than in the single AdipoR2-KO (Figure 2A-B and S2A-C and Table S4) and phospholipids in AdipoR2-KO were more saturated than in AdipoR1-KO (Figure S2D-E). These data are consistent with previous publications showing that AdipoR1/2 deficient cells lack the ability to desaturate fatty acids (Ruiz et al., 2021; Ruiz et al., 2019). Given that the AdipoR1-KO had a less prominent phenotype in both cells and embryos, our later studies mostly focused on AdipoR2-KO and DKO cells.

Excess of SFA in phospholipids leads to increased lipid packing, loss of membrane fluidity and, secondarily, affects several physiological processes (Bakan et al., 2006; Devkota et al., 
2021b). To confirm the excessive membrane packing in AdipoR2-KO and DKO cells, we imaged live MEFs stained with Laurdan dye and calculated their generalized polarization (GP) index (Figure 2C). Interestingly, AdipoR2-KO and DKO MEFs showed little differences compared to WT MEFs under basal conditions, but their GP indexes dramatically increased when challenged with PA in a concentration-dependent manner, indicating extreme lipid packing (Figure 2D-G and S2F). As in the embryos, DKO MEFs showed an aggravated phenotype and their membranes were distinctly more packed than those of AdipoR2-KO MEFs (Figure 2D-E). Strikingly long and thin solid-like structures exclusively appeared in AdipoR2KO and DKO MEFs after PA treatment. We used Bodipy-C12 to confirm the lipidic nature of these abnormal structures (Figure $2 \mathrm{H}$ ) and, given that phospholipids rich in SFA pack tighter and can form solid-like domains in the endoplasmic reticulum (ER) (Shen et al., 2017), we investigated whether the novel structures observed in AdipoR2 deficient MEFs corresponded to ER membranes. For that we co-stained live MEFs with ER-Tracker and Laurdan or Bodipy$\mathrm{C} 12$ and found that the long and thin solid-like structures in the cytoplasm of AdipoR2-KO MEFs correspond indeed to ER membranes (Figure 2I and S2G). Next, we built 2.5D imagereconstructions containing spatial information of the solid-like ER structures in AdipoR2-KO MEFs and found that some were oriented parallel to the culture surface, whereas others stood vertically along the $\mathrm{Z}$-axis (Figure $2 \mathrm{~J}$ ).

To better characterize the membranes in MEFs derived from DKO embryos, we used transmission electron microscopy to image WT and DKO MEFs under basal condition or following PA treatment to challenge the membranes (Figure S2H-K). Electron micrographs of DKO MEFs presented unique spiral membranes in the cytoplasm that were totally absent in WT MEFs, both under basal conditions and upon PA treatment (Figure 2K and S2L-M). The DKO MEFs also had closely apposed membranes in the cytoplasm that increased seven-fold upon PA treatment (Figure S2N-P). Additionally, nuclear envelope budding events, which have been previously identified in cells under several stress conditions (Panagaki et al., 2021), were also present in most of the DKO MEFs upon PA treatment (Figure 2D and S2L-M). These membrane defects are likely ER abnormalities, given the fluorescent microscopy study described above (Figure 2E-J). Overall, these experiments demonstrate that MEFs are a useful model to recreate and study DKO embryonal membrane defects. We next focused on elucidating the molecular mechanisms/pathways by which AdipoR1/2 contribute to membrane homeostasis regulation.

\section{AdipoR1/2 DKO Membrane Defects Are Rescued by Sphingosine 1-Phosphate (S1P)}

AdipoR1/2 possess an intrinsic ceramidase activity in vitro that can catalyze the hydrolysis of ceramides to produce sphingosine and free fatty acids (Vasiliauskaite-Brooks et al., 2017). The resulting sphingosine can be phosphorylated to produce the signaling molecule S1P. Consistent with the AdipoR1/2 ceramidase activity, total ceramides are increased in DKO MEFs, whereas S1P levels are reduced (Holland et al., 2011). On the other hand, over-expression of AdipoR2 in the liver resulted in a significant increase of S1P levels (Holland et al., 2017). Therefore, to follow the hypothesized connection between AdipoR1/2 and S1P, we investigated whether S1P mediates AdipoR1/2 regulation of membrane homeostasis. For that, we challenged DKO MEFs with PA in the presence or absence of exogenously supplied S1P and monitored their membrane composition and properties. Lipidomics analysis showed that S1P significantly 
decreased the amount of PA in PE, whereas it caused an increase in OA and total PUFA in PE (Figure 2M-P and Table S4). Second, Laurdan dye assays confirmed that membranes are less packed in DKO cells treated with S1P (Figure 2Q). Further, it is a well-established observation that increased levels of SFA induce ER-stress (Borradaile et al., 2006; Ruiz et al., 2021) and, in agreement with this, we found that S1P treatment reduced the expression of ER-stress markers Ddit3 and Atf4 (Figure S2S-W).

To further verify our observation that S1P promotes membrane homeostasis, we silenced AdipoR2 expression in HEK293 cells (Figure S3A) then challenged these cells with PA in the presence or absence of S1P. As in MEFs, S1P diminished the saturation levels in membrane phospholipids. More specifically, S1P reduced PA in PC and PE and increased several unsaturated fatty acids: OA in PC and PE, eicosadienoic acid (20:2 n-6) in PC and PalOA in PE (Figure S3B-G and Table S5). Consistently, S1P also improved membrane packing, as indicated by a lower GP index (Figure S3H-I). Moreover, the addition of a fluidizing MUFA, OA, fully compensated the excessive lipid packing caused by PA in AdipoR2-siRNA treated cells (Figure S3I).

Because orthologs of the AdipoR2 protein are conserved in invertebrates, we next asked whether S1P protection against membrane rigidifying conditions is evolutionary conserved. A characteristic phenotype of the $C$. elegans paqr-2 mutants (paqr-2 encodes an AdipoR2 ortholog) is their inability to perform homeoviscous adaptation and grow at $15^{\circ} \mathrm{C}$ (note that wild-type $\mathrm{N} 2$ worms are able to grow between 15 and $25^{\circ} \mathrm{C}$ ) (Svensson et al., 2011). The paqr2 mutants, which arrested as L1 larvae at $15^{\circ} \mathrm{C}$ on standard media, significantly benefitted from the addition of S1P to the culture plate, which allowed them to grow to the L3-L4 stages (Figure 2R-S and S3J). Additionally, the paqr-2 mutants exhibit a characteristic withered morphology of the thin membranous tail tip (Svensson et al., 2011) that was also partially corrected by S1P supplementation (Figure 2T-U). As a consequence of the excess of SFA in membrane phospholipids, paqr-2 mutants also produce an abnormally small brood size accompanied by defects in the germ line (Bodhicharla et al., 2018; Svensson et al., 2011). Remarkably, injection of S1P directly into the gonad of paqr-2 mutant worms partially suppressed their reproduction defects and actually led to a doubling of their brood size (Figure $2 \mathrm{~V}-\mathrm{W}$ ).

Taken together, we conclude that S1P promotes membrane homeostasis and compensates for the absence of the evolutionary conserved membrane fluidity regulator AdipoR2/PAQR-2.

\section{Exogenous S1P Promotes Membrane Homeostasis in PA-Overwhelmed Wild-Type Cells}

Small amounts of PA are particularly toxic to cells/organism lacking AdipoR1/2, but WT cells are also sensitive to high concentrations of PA. Overwhelming amounts of PA cause cell death and membrane rigidity (Devkota et al., 2017; Holland et al., 2011; Listenberger et al., 2003; Ruiz et al., 2019). Therefore, we asked whether S1P can also protect WT cells against excessive amounts of PA. To address this question, we first used WT MEFs and HEK293 cells, treated them with PA $400 \mu \mathrm{M}$ in the presence or absence of S1P and stained them with Laurdan dye. We found that S1P protected MEFs (Figure 3A-B) and HEK293 cells (Figure S4A and Table S6) from PA-induced membrane packing, as indicated by the lower GP index. Note that even though S1P and OA gave a similar overall GP index in MEFs, both treatments were clearly distinguishable: whereas PA+S1P looked similar to vehicle treated cells, PA+OA treated MEFs had very loosely packed membranes (colored in dark blue, indicating low GP index) and 
distinct small areas with high GP index (colored in red), which probably were lipid droplets (Figure 3A). This is consistent with a previous study showing that OA prevents PA-induced apoptosis by channeling PA into TAG (Listenberger et al., 2003).

We also performed fluorescence recovery after photobleaching (FRAP) experiments in live HEK293 cells to assess membrane properties more dynamically. Consistently, S1P improved membrane fluidity in PA treated cells (Figure S4B-C): as little as $10 \mathrm{nM} \mathrm{S1P}$ was enough to significantly promote fluidity in HEK293 cells treated with PA $400 \mu \mathrm{M}$ (Figure S4D and Table S6). OA can be synthesized from PA via PalOA or via stearic acid (18:0) (Figure S4E). Interestingly, WT cells reacted to PA by boosting SCD activity to convert PA into PalOA and hence prioritizing desaturation over elongation (Figure 4C-D, Figure S4F-I and Table S5). In agreement with our model, S1P further promoted desaturation and increased the levels of $\mathrm{PalOA}$ and $\mathrm{OA}$ in $\mathrm{PC}$ and $\mathrm{PE}$, as determined through lipidomics analysis (Figure 4C-D and S4F-I).

Since AdipoR1/2 are ubiquitously expressed, we hypothesized that S1P protection against PA-induced membrane rigidity is not limited to MEFs and HEK293 cells. To test this hypothesis, we used Jurkat E6-1 (human T lymphocyte cell line) and INS-1E (rat pancreatic beta-cell line). Jurkat E6-1 membrane packing, determined using the GP index following Laurdan dye staining, increased in a PA concentration-dependent manner (Figure S4J) and S1P reversed the PA effect (Figure S4K). Similarly, S1P abolished the rigidifying effect of PA in INS-1E cells as measured by FRAP (Table S6) and Laurdan dye staining GP index (Figure $3 \mathrm{E})$. INS-1E cells can be used to monitor insulin secretion, which depends on delicate membrane trafficking and fusion events (Hastoy et al., 2017). PA treatment of INS-1E cells reduced glucose stimulated insulin secretion (GSIS), which again was partially rescued by the addition of S1P (Figure 3F). This result is in line with previous results showing that S1P inhibits PA-induced apoptosis in INS-1 cells (Holland et al., 2011) and in L6 skeletal muscle cells (Botta et al., 2020).

An alternative way to protect WT cells against overwhelming amounts of PA is by overexpressing AdipoR1/2 (Busayavalasa et al., 2020). AdipoR1/2 contain a $\mathrm{Zn}^{2+}$ ion inside the catalytic domain which is essential for their ceramidase activity. In particular, the $\mathrm{Zn}^{2+}$ ion is coordinated by three evolutionary conserved His residues (illustrated in Figure 3G) and the ceramidase activity is hampered when these His are mutated (Tanabe et al., 2015; Vasiliauskaite-Brooks et al., 2017). Therefore, we used HEK293 cells to over-express mutated forms of AdipoR2 in which one of the His (H348) or all three of them (H202, H348 and H350) were changed to Ala (Figure 3G-H). Next, we confirmed the expression of the constructs by Western-blot (Figure 3H) and then assessed membrane health. We found that while the wildtype AdipoR2 and the single H348A mutant AdipoR2 efficiently protected HEK293 cells against the membrane-rigidifying effects of PA, the triple His mutant did not (Figure 3I). Similarly, we used paqr-2 mutant worms to over-express WT PAQR-2::GFP or PAQR-2::GFP versions where one or all of the zinc coordinating His were mutated. We first confirmed their expression (Figure S4L) and then challenged their membranes by growing the worms at $15^{\circ} \mathrm{C}$ or in presence of glucose (note that glucose is readily converted to SFA by the dietary E. coli; (Devkota et al., 2017)). In both experiments, the WT and PAQR-2::GFP H511A single His mutant protected against the membrane-rigidifying challenged while the PAQR-2::GFP H365A, H511A, H515A triple His mutant did not (Figure S4M-N). Similarly, the PAQR-2 
triple His mutant did not rescue the deformed tail phenotypes of the paqr-2 mutant (Figure $\mathrm{S} 4 \mathrm{O})$.

Altogether, our results demonstrate that S1P promotes membrane fluidity and suggest that the AdipoR2 ceramidase activity is evolutionary conserved and essential for signaling through S1P.

\section{Sphingosine Kinases Are Required for Membrane Homeostasis}

It has been proposed that sphingosine kinases (Sphk1 and Sphk2) mediate AdipoR1/2 response (Holland et al., 2011), though this had not yet been experimentally tested. To begin to understand the role of Sphk1/2 in membrane fluidity, we knocked-down Sphk1 and Sphk2 expression in HEK293 cells (Figure S4P-Q) and assessed membrane health. Interestingly, single siRNA against Sphk1 or Sphk2 (Figure S4P-Q) did not affect membrane packing either in basal conditions or upon PA treatment (Table S6 and Figure 4A). However, membrane packing was notably increased after simultaneous knockdown of Sphk1 and Sphk2 (Table S6 and Figure 4A). A single sphingosine kinase has been identified so far in C. elegans and the corresponding sphk-1 mutant worms had more rigid membranes as measured by FRAP (Figure 4 B-D). Accordingly, the sphk-1 mutant was sensitive to PA-loaded bacteria: sphk-1 mutant worms grew slower and showed a tail tip morphology defect similar to that of the paqr-2 mutant (Figure 4E-F and Table S6). Note however that the growth and tail tip phenotypes of the sphk-1 mutant were not as severe as in the paqr-2 mutant, suggesting that worms may have a second yet unidentified sphingosine kinase. Importantly, the addition of S1P to the cell culture rescued the phenotypes caused by Sphk1/2 silencing in HEK293 cells (Figure 4G-H). Altogether, these results are consistent with sphingosine kinase activity being an evolutionary conserved effector of AdipoR1/2 during membrane homeostasis.

\section{Parallel Activation of S1PR3 and PPAR $\gamma$ by S1P Mediates AdipoR2 Membrane Protection}

Multiple pathways mediate S1P biological actions. Canonical S1P signaling starts with the activation of one of the five S1P membrane receptors (S1PR1-5) (Blaho and Hla, 2014), but S1P intracellular targets have also been discovered (Chakraborty et al., 2019; Parham et al., 2015) (Figure S5A). We therefore sought to elucidate which pathway(s) are relevant for AdipoR2-S1P membrane homeostasis.

To investigate whether S1PR1-5 regulate membrane properties, we first determined the expression levels of the S1PRs in MEFs. We detected a strong expression of S1PR3, moderate expression of S1PR1-2, and no expression of S1PR4-5 (Figure 5A). Then, we selected specific S1PR agonist/antagonist (Figure S5B) and assessed their effects on membrane health using Laurdan dye. TY52156, a specific S1PR3 antagonist caused PA sensitivity and increased membrane packing in MEFs, as indicated by a higher GP index (Figure 5B-C). In contrast, SEW2871 and W146, S1PR1 agonist and antagonist respectively, or JTE-01, a S1PR2 antagonist, did not modify the MEFs response to PA (Figure 5C and S5C-D). To further strengthen our observation concerning the S1PRs, we carried out similar experiments in HEK293 and U-2 OS cells. Expression of S1PR1,2,3 and 5, but not S1PR4, was detected in HEK293 cells (Figure S5E). Again, the S1PR3 antagonist TY52156 enhanced the sensitivity of HEK293 cells to PA (Figure S5F), while the S1PR2 antagonist JTE-013 and the S1PR5 
agonist A971432 did not influence membrane packing (Figure S5F-G). Equivalent experiments with the U2 O-S cells produced results similar to those in HEK293 cells. Specifically, we detected the expression of S1PR1, 2, 3 and 5 in U-2 OS cells (Figure S5H) and TY52156 was the only S1PR pharmacological intervention able to modify membrane packing (Figure S5I). Next, we took a genetic approach and used siRNA against S1PR1-3 in HEK293 (Figure S5JL). In agreement with the pharmacological treatments, silencing of S1PR3 increased membrane packing (Figure 5D) while S1PR1 or S1PR2 siRNA did not (Figure 5D and S5M).

S1PRs are G-protein-coupled receptors, and S1PR3 is able to couple with three different G protein classes and thus activate multiple downstream effectors. More specifically, S1PR3 activation leads to the phosphorylation of PI3K and AKT (Ruiz et al., 2017b), with AKT being a well-known activator of the sterol regulatory element-binding protein-1 (SREBP1) (Porstmann et al., 2008). SREBP1 is a transcription factor that controls the expression of enzymes required for endogenous cholesterol, fatty acids, and phospholipid synthesis (Eberle et al., 2004). We have previously shown that SREBF1 silencing reduces $S C D$ expression, which results in membranes rich in SFA-containing phospholipids and membrane rigidification (Ruiz et al., 2021). Here, we first treated WT MEFs with betulin and confirmed that SREBP inactivation increases membrane packing in these cells (Figure S5N). The SREBP pathway is evolutionarily conserved and, in C. elegans, a partial loss of function of SBP-1 (SBP-1 is the SREBP1 ortholog in C. elegans and null alleles are lethal) caused PA sensitivity: $s b p-1$ mutant worms grew slower and showed a tail tip defect similar to that of paqr-2 mutants when grown on PA-loaded bacteria plates (Figures 5E-F and Table S6). Next, we found that supplementation of S1P could not rescue the membrane packing defects caused by the loss of SREBP1 (Figure 5G and S5O), which is consistent with SREBP1 acting downstream of AdipoR2 and S1P. We then sought to determine whether S1P modulates SREBP1 processing. PA treatment reduced the amount of the unprocessed SREBP1 form (the inactive form of the transcription factor) in HEK293 cells, which was partially restored by S1P (Figure 5H). Similarly, the levels of unprocessed SREBP1 were reduced in AdipoR2-lacking cells, but was boosted by S1P treatment (Figure S5P).

Altogether, these results indicate that AdipoR2-derived S1P acts via S1PR3 and SREBP1 to promote fatty acid desaturation and adequate membrane fluidity.

The transcription factor PPAR $\gamma$ is a master regulator of lipid metabolism (Varga et al., 2011) and is one of the intracellular targets of S1P (Chakraborty et al., 2019; Parham et al., 2015). More specifically, S1P binding to PPAR $\gamma$ promotes its binding to peroxisome-proliferator response elements and subsequent transcription (Lee et al., 2017). Therefore, we next investigated the possible role of PPAR $\gamma$ in membrane fluidity regulation and its connection with AdipoR2 and S1P. MEFs, either WT or AdipoR2-KO, were more sensitive to low doses of PA when treated with the PPAR $\gamma$ antagonist T0070907 and showed increased GP index (Figure 6A-B and Figure S6A). Likewise, the membranes of U-2 OS cells were excessively packed after T0070907 treatment (Figure S6B). Next, we silenced the expression of PPAR $\gamma$ in HEK293 cells (Figure S6C) and quantified membrane fluidity by FRAP and Laurdan. Both techniques showed that PPAR $\gamma$-deficient cells had more rigid membranes when exposed to PA and that the addition of S1P to the culture medium was not sufficient to rescue this membrane phenotype (Figure 6C and S6D). Importantly, PPARs function as obligate heterodimers with 
other nuclear transcriptions factors such as retinoid X receptor (RXR) (Varga et al., 2011) and, as expected, the loss of $\operatorname{RXR} \alpha$ mimicked the absence of PPAR $\gamma$ : we noticed excessive membrane packing upon silencing of RXR $\alpha$ and importantly, this could not be rescued by S1P (Figure S6E-F and Table S6). Together, these results are consistent with PPAR $\gamma / \mathrm{RXR} \alpha$ acting downstream of AdipoR2 and S1P.

Given that AdipoR2 has been shown to be associated with increased activity of another member of PPAR family, namely PPAR $\alpha$ (Yamauchi et al., 2007), we explored whether there was any connection between PPAR $\alpha$ and membrane fluidity regulation. For that, we used siRNA to silence PPAR $\alpha$ in HEK293 cells (Figure S6G) followed by FRAP and Lipidomics. We found that the absence of PPAR $\alpha$ did not alter membrane fluidity or phospholipid composition (Figure S6H-M and indicates that PPAR $\alpha$ is not part of the mechanisms responsible for membrane fluidity regulation.

In evolutionary terms, it has been shown that NHR-49 in C. elegans has a prominent role in modulating lipid metabolism and is typically referred to as a functional ortholog of PPAR $\alpha$ in that organism (Van Gilst et al., 2005; Wani et al., 2021), although NHR-49 is still considered to be an orphan receptor. Worms lacking NHR-49 recapitulated several paqr-2 mutant phenotypes: they had rigid membranes, grew slower on PA-loaded bacteria and had the characteristic tail tip morphology defect (Figure 6D-F). To test whether S1P may function as an NHR-49 ligand, we first tagged the endogenous NHR-49 with GFP by using CRISPR/Cas9 genome editing. Fluorescent microscopy revealed the nuclear localization of this NHR-49 reporter in the intestinal and hypodermal cells, further confirmed by colocalization with the nuclear marker tdTomato::H2B (Figure S6N-Q). Interestingly, worms grown on normal plates presented a small percentage of cells with a distinct focus within the nucleus (Figure 6G and $\mathrm{S} 6 \mathrm{P}$ ), which is likely the nucleolus. We then found that WT worms grown on PA-loaded bacteria responded by increasing the number of nuclei with such foci, but that paqr-2 mutant was unable to replicate such a dynamic translocation (Figure $6 \mathrm{H}$ ). Importantly, the addition of S1P to the plate boosted the percentage of nuclei with foci in paqr-2 mutants both at room temperature and at $15^{\circ} \mathrm{C}$ (Figure 6I-J). Altogether, our experiments indicate that NHR-49 is the functional ortholog of PPAR $\gamma$ with respect to membrane homeostasis and that its sub-nuclear localization can be modulated by S1P.

In summary, we conclude that AdipoR2-derived S1P signals in parallel through S1PR3SREBP and PPAR $\gamma$ to promote membrane homeostasis and that this pathway is evolutionary conserved.

\section{SCD Expression and Fatty Acid Desaturation Are the Final Outputs of the AdipoR2-S1P Signaling}

The $\Delta-9$ desaturase SCD is responsible for converting SFA into MUFA and is essential to sustain the levels of unsaturated fatty acids required for membrane homeostasis (Devkota et al., 2017; Ruiz et al., 2021). Remarkably, an RNAseq experiment previously showed that SCD is the most robustly downregulated gene in AdipoR2-KO HEK293 cells (Ruiz et al., 2021). Likewise, in C. elegans, it has been shown that paqr-2 mutant worms have reduced expression of the SCD ortholog fat-7 (Svensk et al., 2013). Here, we confirmed that fat-7 is downregulated in paqr-2 mutant worms (Figure 7 and S7A-B) and also quantified the expression of the other 
two $\Delta-9$ desaturases in $C$. elegans, namely fat-5 and fat-6, and found that these were also downregulated in the paqr-2 mutant (Figure S7C-D). Consistently with our model, other mutations/siRNA in the AdipoR2-S1P pathway caused down-regulation of $\Delta-9$ desaturases. More specifically, sphk-1, sbp-1, nhr-49 mutations in worms and PPAR $\gamma$ siRNA in HEK293 cells reduced the expression of $\Delta-9$ desaturases (Figure 7A and S7B-E). As a consequence of reduced desaturase expression, the paqr-2, sbp-1 and $n h r-49$ mutants all had increased amounts of SFA in membrane phospholipids at the expense of PUFA (Figure 7B-C and Table S7) (note that $C$. elegans have the ability to synthesize PUFA and hence 18:2 and 18:3 are not essential fatty acids as in humans (Watts and Ristow, 2017)). Importantly, S1P boosted fat-7 expression in paqr-2 mutants (Figure 7D-E and S7F), which likely contributes to its above-described ability to rescue several membrane related phenotypes (Figure $2 \mathrm{R}-\mathrm{W}$ ).

To further verify the role of SCD as final output of the AdipoR2-S1P pathway, we assessed the importance of SCD activity using lipidomics analysis. In agreement with our model, the loss of AdipoR2 (upstream of S1P) resulted in an excess of SFA that was partially corrected by S1P, which increased the total amount of MUFA in PE and OA in PC at the expense of PA. However, the absence of PPAR $\gamma$ or SCD (downstream of S1P) resulted in an excess of SFA that was not rescued by S1P (Figure 7F-G, S7G-H and Table S5). Accordingly, the Laurdan dye staining showed that $\mathrm{S} 1 \mathrm{P}$ did not suppress the excessive lipid-packing/membrane rigidity caused by the lack of SCD (Figure 7H and S7I), indicating that SCD is necessary for the effects of S1P on membrane homeostasis.

\section{DISCUSSION}

Since the initial cloning of the AdipoR1/2 (Yamauchi et al., 2003) the field has been mostly focused on the antidiabetic effects of these proteins (Bjursell et al., 2007; Holland et al., 2017; Yamauchi et al., 2007). However, there is a mounting number of evidences showing that the primary and evolutionary conserved function of the AdipoR $1 / 2$ proteins is to regulate cell membrane composition to maintain its fluidity (reviewed on Pilon, 2021).

A major finding of our work is the elucidation of the detailed molecular pathway by which cells regulate membrane homeostasis. Our results are consistent with the previous hypothesis that S1P is a mediator of AdipoR1/2 function (Holland et al., 2011) and links the documented ceramidase activity of the AdipoR1/2 (Vasiliauskaite-Brooks et al., 2017) with its primary function as fluidity regulator (Devkota et al., 2017; Ruiz et al., 2021). In particular, we propose that AdipoR1/2 derived S1P leads to the activation of the transcription factors SREBP1 and PPAR $\gamma$ to upregulate SCD expression and hence to the promotion of membrane fluidity. PPAR $\gamma$ is a well-established regulator of lipid and glucose metabolism, however, most of the studies mainly focused on the role of PPAR $\gamma$ as a transcriptional controller of adipocyte differentiation and immune response (Varga et al., 2011). Here, we found a new major role for $\operatorname{PPAR} \gamma$, namely that it controls membrane homeostasis in multiple cell types. This is particularly interesting given that the functions of the broadly expressed isoform of PPAR $\gamma$ are not fully understood. Our work now suggests that PPAR $\gamma$ can regulate lipid metabolism through two different processes: (1) increase fat storage by defining adipocyte identity and (2) maintenance of membrane properties. Probably, these two outputs of PPAR $\gamma$ activation rely on different upstream activators and our work indicates that S1P is responsible for PPAR $\gamma$ dependent promotion of membrane homeostasis. 
DKO embryonic lethality in mice was previously reported in (Lindgren et al., 2013), but not further investigated. We have systematically characterized DKO embryos using histology, proteomics and lipidomics. Our observations show that, in line with the earlier reports in cultured cells and C. elegans, the saturation of membrane phospholipids likely explains the DKO embryonic lethality. This highlights the vital importance of AdipoR2-meditated membrane homeostasis and AdipoR1/2 in a mammalian physiological context by the first time. Additionally, we also identified numerous metabolic related defects in the DKO embryos, including reduced levels of apolipoproteins suggestive of poor lipid exchange among DKO tissues. It is noteworthy, that ApoB ablation also causes embryonic lethality (Farese et al., 1995), as is also the case for PPAR $\gamma$ (Barak et al., 1999), SREBPs (Horton et al., 2002) and Sphk1/2 double null embryos (Mizugishi et al., 2005). The lethality of these mutants demonstrates that membrane homeostasis is essential for the normal development of mouse embryos.

The AdipoR1-KO and AdipoR2-KO mice used in the present work were generated by Deltagen and have been studied in multiple laboratories (Bjursell et al., 2007; Holland et al., 2011; Liu et al., 2007; Osada et al., 2021; Rice et al., 2015). However, these are not the only AdipoR knockouts mice described in the literature: another set of independently produced genomic lesions in the AdipoR1/2 genes has been generated and these DKO mice are viable (Yamauchi et al., 2007). Given that AdipoR proteins are undetectable in both null-mutant models (Bjursell et al., 2007; Iwabu et al., 2021; Lindgren et al., 2013) and considering the large number of genes participating in lipid metabolism, the different phenotypes could be explained by variations in the genetic background. Therefore, it would be interesting to test whether this other independently generated DKO mice also have increased SFA in membrane phospholipids and rigid membranes, but not quite enough to cause lethality/serious defects.

Although AdipoR1-KO embryos/MEFs showed a relatively mild membrane defect phenotype, the consequences of AdipoR1 mutations can be still dramatic in the adult or in specific tissues. For instance, single amino acid mutation of AdipoR1 occurs in different forms of retinitis pigmentosa (Xu et al., 2016; Zhang et al., 2016) and AdipoR1-KO mice have a substantial degeneration of photoreceptors and visual impairment as early as 3 weeks of age that is due to the lack of PUFA in membrane phospholipids (Osada et al., 2021; Rice et al., 2015). This provides an independent confirmation that the AdipoR pathway is essential for membrane homeostasis, and shows that AdipoR1 has a specialized role in the maintenance of PUFA levels in the retina.

Finally, it will be of interest to understand whether our findings have therapeutic implications. For instance, pharmacological activation of AdipoR1/2 (as nicely ilustrated in Iwabu et al., 2021; Onodera et al., 2021) could be exploited to treat pathologies that correlate with abnormally elevated levels of SFA in phospholipids and membrane properties changes, such as diabetes (reviewed in Pilon, 2016). However, the ability of the current AdipoR1/2 agonists to modulate membrane homeostasis remains to be investigated.

\section{ACKNOWLEDGMENTS}

We thank Rafael Camacho and the Centre for Cellular Imaging (CCI) at the University of Gothenburg and the National Microscopy Infrastructure, NMI (VR-RFI 2016-00968) for assistance in microscopy. The Proteomics Core Facility at Sahlgrenska Academy, University 
of Gothenburg performed the analysis for protein quantification. Some C. elegans strains were provided by the Caenorhabditis elegans Genetics Center. We also thank Clotilde Wiel and Volkan Sayin for helping with scanning the histological sections. Cristina Fernandez and Irene Cozar for the GSIS protocol. Beatriz Martinez-Abad and Malin Johansson for helping with the flow cytometry experiments. Anton Rydberg for technical help with some qPCRs and Valentina Sukonina, Sven Enerbäck, Lisa Nilsson, Jonas Nilsson, Andrej Besse and Lenka Besse for sharing different cell lines.

This work was supported by: Swedish Research Council (Vetenskapsrådet Dnr: 2020-03300 and 2015-00560), Cancerfonden (Dnr: 190029 Pj), Kungliga Vetenskaps- och VitterhetsSamhället i Göteborg (2020-462), Stiftelserna Wilhelm och Martina Lundgrens (2020-3610) and Åke Wibergs Stiftelse (M20-0151).

\section{AUTHOR CONTRIBUTION}

Conceptualization, MR, RD, MP; Investigation MR, RD, DP, POB, DK, MH, AN; Writing Original Draft MR; Writing - Review \& Editing, MR, MP; Funding Acquisition, MR, JB, MP; Resources, KP, JLH, MBY, PC, JB. All authors approved the final version of the manuscript.

\section{DECLARATION OF INTERESTS}

KP and MB: Affiliated with AstraZeneca. The other authors declare that no competing interests exist.

\section{METHODS}

\section{CONTACT FOR REAGENT AND RESOURCE SHARING}

Unique reagents generated in this study are available to any researcher upon request. Further information and requests for resources and reagents should be directed to the Lead Contact, Mario Ruiz (mario.ruiz.garcia@gu.se).

\section{EXPERIMENTAL MODEL AND SUBJECT DETAILS}

\section{Mouse Strains}

Heterozygous AdipoR1 and AdipoR2 gene knockout mice were obtained from Deltagen. Genomic lesions are described in (Bjursell et al., 2007). Mutations were maintained on C57Bl/6 background. Experiments were approved by the Gothenburg Animal Ethics Committee (\#2311/19). Mice were kept under temperature-controlled conditions with free access to water and standard rodent chow (12\% of calories from protein, $12 \%$ from fat, and $66 \%$ from carbohydrates) with a $12 \mathrm{~h}$ light $-12 \mathrm{~h}$ dark cycle.

\section{Cell lines}

The cell line INS-1E was kindly provided by V. Sukonina and S. Enerbäck, the Jurkat E6-1 cell line by L. Nilsson and J. Nilsson (all at the University of Gothenburg, Sweden) and the OS U-2 cell line by A. Besse and L. Besse (Cantonal Hospital St. Gallen, Switzerland). HEK293 cells were purchased from the ATCC. 


\section{Cell culture conditions}

Mouse Embryonic Fibroblast (MEFs) and HEK293 cells were maintained in the DMEM medium (Gibco) containing glucose $1 \mathrm{~g} / \mathrm{L}$, pyruvate and GlutaMax and supplemented with 10\% fetal bovine serum (HyClone) and 1\% non-essential amino acids, HEPES $10 \mathrm{mM}$ and 1\% penicillin and streptomycin (all from Life Technologies). Human U-2 OS cells as HEK293 but glucose was at $4.5 \mathrm{~g} / \mathrm{L}$. Jurkat E6-1 were grown in RPMI 1640 medium with GlutaMax (Gibco) and supplemented with $10 \%$ fetal bovine serum and $1 \%$ penicillin and streptomycin. INS-1E cells were cultivated as Jurkat plus HEPES $10 \mathrm{mM}$ and $0.05 \mathrm{mM}$ 2-mercaptoethanol (Sigma). All cells were maintained at $37^{\circ} \mathrm{C}$ in a water-humidified $5 \% \mathrm{CO}_{2}$ incubator. Cells were subcultured two or three times per week at $90 \%$ confluence, and cultivated on treated plastic flasks and multi-dish plates (Nunc). For FRAP and Laurdan dye experiments, cells were seeded in glass bottom dishes (Ibidi).

\section{C. elegans strains}

C. elegans strains were cultured as in (Brenner, 1974). The wild-type C. elegans reference strain N2, paqr-2(tm3410), sphk-1(ok1097), nhr-49(gk405) and sbp-1(ep79) and the transgene carrying strain EG7865 \{oxTi617 [eft-3p::tdTomato::H2B::unc-54 3'UTR + Cbr-unc$119(+)]\}$ are available from the $C$. elegans Genetics Center (CGC; USA). The pfat$7:: G F P(r t I s 30)$ carrying strain HA1842 was a kind gift from Amy Walker (Walker et al., 2011).

The PHX3258 (nhr-49::GFP) strain was created by Suny Biotech (Fuzhou City, China) using CRISPR/Cas9 and carries a modified nhr-49 locus where the end of the coding region is fused in-frame with that of GFP. The altered sequence is as follows (underlined sequences are from the endogenous nhr-49, linker sequences are in bold, GFP coding sequences are in regular uppercase, introns and 3'UTR are in lowercase, and the STOP codon is in italics): TTGAACAGTGAGCAGAATAATCATATGCTCAGTAAAGGAGAAGAACTTTTCAC TGGAGTTGTCCCAATTCTTGTTGAATTAGATGGTGATGTTAATGGGCACAAATTT TCTGTCAGTGGAGAGGGTGAAGGTGATGCAACATACGGAAAACTTACCCTTAAA TTTATTTGCACTACTGGAAAACTACCTGTTCCATGGgtaagtttaaacatatatatactaactaaccetg attatttaaattttcagCCAACACTTGTCACTACTTTCTgTTATGGTGTTCAATGCTTcTCgAGA TACCCAGATCATATGAAACgGCATGACTTTTTCAAGAGTGCCATGCCCGAAGGTT ATGTACAGGAAAGAACTATATTTTTCAAAGATGACGGGAACTACAAGACACgtaag tttaaacagttcggtactaactaaccatacatatttaaattttcagGTGCTGAAGTCAAGTTTGAAGGTGATAC CCTTGTTAATAGAATCGAGTTAAAAGGTATTGATTTTAAAGAAGATGGAAACATT CTTGGACACAAATTGGAATACAACTATAACTCACACAATGTATACATCATGGCA GACAAACAAAAGAATGGAATCAAAGTTgtaagtttaaacatgattttactaactaactaatctgatttaaattttc agAACTTCAAAATTAGACACAACATTGAAGATGGAAGCGTTCAACTAGCAGACCA TTATCAACAAAATACTCCAATTGGCGATGGCCCTGTCCTTTTACCAGACAACCAT TACCTGTCCACACAATCTGCCCTTTCGAAAGATCCCAACGAAAAGAGAGACCAC ATGGTCCTTCTTGAGTTTGTAACAGCTGCTGGGATTACACATGGCATGGATGAAC TATACAAATAAtaattccattttttctcccaaaactcttcacctcat.

\section{C. elegans culture conditions}


Unless otherwise stated, experiments were performed at $20^{\circ} \mathrm{C}$, using the E.coli strain OP50 as food source, which was maintained on LB plates kept at $4^{\circ} \mathrm{C}$ (re-streaked every 6-8 weeks), and single colonies were picked for overnight cultivation at $37^{\circ} \mathrm{C}$ in $\mathrm{LB}$ medium before being used to seed NGM (nematode growth media) plates (Sulston and Hodgkin, 1988). Plates containing glucose or S1P were prepared by adding the respective stock solutions to cooled NGM after autoclaving.

\section{METHOD DETAILS}

\section{Mouse Crosses and Embryo Obtention}

AdipoR1 and AdipoR2 heterozygous animals were crossed to generate double heterozygous, that were further crossed to obtain E12.5 and E15.5 embryos. Tail biopsies were used for genotyping (see primers in list). Platinum ${ }^{\text {TM }}$ II Hot-Start Green PCR Master Mix (2X) (Thermo Scientific) was used for the genotyping.

\section{Histology}

E12.5 embryos were fixed in 4\% buffered paraformaldehyde. Then the tissues were embedded in paraffin, sectioned, and stained with hematoxylin and eosin by Histocenter (Gothenburg, Sweden). Sections were scanned with a Zeiss Axio Scan.Z1 Slide Scanner.

\section{MEFs isolation}

The body of E12.5 embryos was maintained in cold PBS during genotyping and then tissues of interest were digested with Trypsin (Sigma) for $5-10 \mathrm{~min}$ at $37^{\circ} \mathrm{C}$ and homogenized by pipetting and seeded in a 6 well-plate for $24 \mathrm{~h}$ and further expanded.

\section{Gene Silencing in HEK293 Cells}

The following pre-designed siRNAs were purchased from Dharmacon: AdipoR2, Non-Target, PPARA, PPARG, RXRA, S1PR1, S1PR2, S1PR2, SCD, Sphk1, Sphk2, SREBF1 and SREBF2. Transfection of $25 \mathrm{nM}$ siRNA was performed in complete media using Viromer Blue according to the manufacturer's instructions $1 \mathrm{X}$ (Lipocalyx). Knockdown gene expression was verified by qPCR $48 \mathrm{~h}$ after transfection.

\section{Fatty Acid (FA) and Sphingosine 1-Phosphate (S1P) Treatments: Cell Cultures}

Palmitic acid (PA) and oleic acid (OA) were dissolved in sterile DMSO then mixed with fatty acid-free bovine serum albumin (BSA) (all from Sigma) in serum-free medium for 15 min at room temperature (Ruiz et al., 2021; Ruiz et al., 2019). The molecular ratio of BSA to PA was 1 to 5.3 when using $400 \mathrm{mM}$ palmitic acid, and 1 to 2.65 when using $200 \mathrm{mM}$ palmitic acid. Cells were then cultivated in this serum-free media containing palmitic acid for 6,18 or $24 \mathrm{~h}$ prior to analysis. An equivalent percentage of DMSO was used as a vehicle control in the experiments. S1P (Avanti Lipids) was dissolved in serum-free medium containing fatty acid free BSA and sonicated in a water bath at $37^{\circ} \mathrm{C}$. S1P aliquots were prepared at $100 \mu \mathrm{M}$ and stored at $-80^{\circ} \mathrm{C}$.

\section{Chemical Agonist/Antagonist}


A971432 (S1PR5 agonist), JTE013 (S1PR2 antagonist), SEW2871 (S1PR1 agonist), TY52156 (S1PR3 antagonist), T0070907 (PPAR $\gamma$ antagonist) (all from Tocris) and betulin (inhibitor of SREBP maturation, from Sigma) were dissolved in DMSO. W146 (S1PR1 antagonist) was dissolved in ethanol. An equivalent percentage of DMSO/ethanol was used as a vehicle control in the experiments.

\section{Pre-Loading of $E$. coli with PA}

Stocks of $100 \mathrm{mM}$ PA dissolved in ethanol were diluted in LB media to final concentrations of $2 \mathrm{mM}$, inoculated with OP50 bacteria, then shaken overnight at $37^{\circ} \mathrm{C}$. The bacteria were then washed twice with M9 to remove unloaded fatty acids and growth media, diluted to equal OD600, concentrated 10 times by centrifugation, resuspended in M9 and seeded onto NGM plates lacking peptone (Devkota et al., 2017).

\section{S1P plates and S1P injections in $C$. elegans}

S1P (Avanti Lipids) was dissolved in butanol:methanol (3:1) and sonicated in a water bath at $55^{\circ} \mathrm{C}$. S1P stock solution $(1.32 \mathrm{mM})$ was further stored at $-80^{\circ} \mathrm{C}$. Plates containing S1P were prepared by adding stock solution of S1P to cooled NGM after autoclaving (Lee et al., 2020). For injections, $1 \mu \mathrm{M} \mathrm{S1P}$ was directly injected into the $C$. elegans gonad.

\section{Electron Microscopy (EM) of MEFs}

MEFs were prepared using high-pressure freezing followed by freeze substitution. Cells were centrifuged into a sealed pipet tip for better concentration of sample before transfer into the carrier, as described in (McDonald et al., 2010). Samples were then loaded into aluminum specimen carriers ( $0.1 \mathrm{~mm}$ cavity) with a hexadecane-coated flat carrier as a lid and were highpressure frozen in a Wohlwend Compact 3 machine. A short freeze substitution protocol was applied, using 2\% uranyl acetate dissolved in acetone (UA; from 20\% UA stock in methanol) for one hour (Hawes et al., 2007) \{Panagaki, 2021 \#113\}. The UA incubation was followed by two washes in $100 \%$ acetone, first wash for one hour and last wash over-night. Simultaneously, the temperature was raised from $-90^{\circ} \mathrm{C}$ to $-50^{\circ} \mathrm{C}$ overnight with a rate of $3{ }^{\circ} \mathrm{C} / \mathrm{h}$. Samples were then infiltrated with HM20 resin in increasing concentrations of $20 \%, 40 \%, 50 \%, 80 \%$ in acetone and finally three times in $100 \%$ resin ( $2 \mathrm{~h}$ per solution). Polymerization of the plastic occurred over $48 \mathrm{~h}$ using UV light at $-50^{\circ} \mathrm{C}$ followed by $48 \mathrm{~h}$ in room temperature. Samples were sectioned in $70 \mathrm{~nm}$ thin sections and placed on copper slot grids. Sections were stained with $2 \%$ UA for 5 minutes and Reynold's lead citrate for 1 minute (Reynolds, 1963). Grids were washed in $3 \mathrm{x} \mathrm{dH}_{2} \mathrm{O}$ between each staining solution. All thin sections were imaged at 120 $\mathrm{kV}$ on a Tecnai $\mathrm{T} 12$ transmission electron microscope equipped with a Ceta CMOS 16M camera (Thermo Fisher). Images were analyzed and prepared using the IMOD software package (Kremer et al., 1996).

\section{Lipidomics}

Mouse embryo were extracted and maintained in ice until the head was collected and immediately froze in dry ice. Tissues were stored at $-80^{\circ} \mathrm{C}$ until analysis. MEFs and HEK293 cells (prepared in at least three independent replicates) were cultivated in basal and the presence of palmitic acid for 18 or $24 \mathrm{~h}$ prior to harvesting using TrypLE Express (Gibco), washed with 
PBS and stored at $-80^{\circ} \mathrm{C}$ until analysis. For worms Lipidomics, samples were composed of synchronized L4 larvae (one $9 \mathrm{~cm}$ diameter plate/ sample; each treatment/genotype was prepared in four independently grown replicates) grown on non-peptone plates seeded with OP50 and OP50 pre-loaded with PA. Worms were washed three times with M9, pelleted and stored at $-80^{\circ} \mathrm{C}$ until analysis. For lipid extraction, the cell pellet was sonicated for $10 \mathrm{~min}$ in methanol and then extracted according to published methods (Lofgren et al., 2016). Internal standards were added during the extraction. Phospholipids and sphingomyelins were measured using direct infusion mass spectrometry. For phospholipids, a part of the lipid extracts were evaporated and reconstituted in chloroform:methanol [1:2] with $5 \mathrm{mM}$ ammonium acetate. This solution was infused directly (shotgun approach) into a QTRAP 5500 mass spectrometer (Sciex) equipped with a with a TriVersa NanoMate (Advion Bioscience) as described previously (Jung et al., 2011). A similar procedure was used for sphingomyelin. However, prior to analysis the lipid extracts were evaporated and exposed to alkaline hydrolysis $(0.1 \mathrm{M} \mathrm{KOH}$ in methanol for 60 minutes) in order to remove the interfering phospholipids. For phosphatidylcholines and sphingomyelins mass spectra were attained in precursor ion scanning mode using the phosphocholine headgroup $(\mathrm{m} / \mathrm{z}$ 184.1) as fragment ion. For phosphatidylethanolamines neutral loss scanning of $\mathrm{m} / \mathrm{z} 141.1$ was used (Ejsing et al., 2009; Ekroos et al., 2003) and TAGs were measured using neutral loss scanning (Murphy et al., 2007). Ceramides, dihidroceramides, glucosylceramides and lactosylceramides were measured using ultra performance liquid chromatography coupled to tandem mass spectrometry according to previous publication (Amrutkar et al., 2015). Free cholesterol was quantified using straight phase HPLC coupled to ELS detection according to previous publication (Homan and Anderson, 1998). The data were evaluated using the LipidView and MultiQuant softwares (Sciex). Qlucore Omics Explorer software was used for the multivariant analysis. The complete lipid composition data are provided in supplementary tables.

\section{Proteomics}

Sample preparation for proteomic analysis: Samples were homogenized on a FastPrep-24 instrument (MP Biomedicals) for 5 repeated 40 second cycles at $6.5 \mathrm{~m} / \mathrm{s}$ in lysis buffer containing 2\% SDS, $50 \mathrm{mM}$ triethylammonium bicarbonate (TEAB). Lysed samples were centrifuged at $21100 \mathrm{~g}$ for $10 \mathrm{~min}$ and the supernatants were transferred to clean tubes. Protein concentrations were determined using Pierce BCA Protein Assay Kit (Thermo Scientific) and a Benchmark Plus microplate reader (Bio-Rad). Aliquots containing $30 \mu \mathrm{g}$ of total protein from each sample were incubated at $56^{\circ} \mathrm{C}$ for $30 \mathrm{~min}$ in the lysis buffer with DTT at $100 \mathrm{mM}$ final concentration. The reduced samples were processed using the modified filter-aided sample preparation (FASP) method (Wisniewski et al., 2009). In short, the reduced samples were diluted to $1: 4$ by $8 \mathrm{M}$ urea solution, transferred onto Nanosep 30k Omega filters (Pall Corporation) and washed repeatedly with $8 \mathrm{M}$ urea and once with digestion buffer $(0.5 \%$ sodium deoxycholate in $50 \mathrm{mM}$ TEAB). Free cysteine residues were modified using $10 \mathrm{mM}$ methyl methanethiosulfonate (MMTS) solution in digestion buffer for $20 \mathrm{~min}$ at RT and the filters were washed twice with $100 \mu 1$ of digestion buffer. Pierce trypsin protease (MS Grade, Thermo Scientific) in digestion buffer ( $0.5 \%$ sodium deoxycholate in $25 \mathrm{mM}$ TEAB) was added at a ratio of 1:100 relative to total protein mass and the samples were incubated at $37^{\circ} \mathrm{C}$ for $3 \mathrm{~h}$. An additional portion of trypsin was added and incubated overnight. The peptides were 
collected by centrifugation and isobaric labeling was performed using Tandem Mass Tag (TMT-10plex) reagents (Thermo Scientific) according to the manufacturer's instructions. The labelled samples were combined into one pooled sample, concentrated using vacuum centrifugation, and SDC was removed by acidification with 10\% TFA and subsequent centrifugation. The labelled pooled sample was treated with Pierce peptide desalting spin columns (Thermo Scientific) according to the manufacturer's instructions. The purified desalted sample was pre-fractionated into 40 primary fractions with basic reversed-phase chromatography (bRP-LC) using a Dionex Ultimate 3000 UPLC system (Thermo Scientific). Peptide separations were performed using a reversed-phase XBridge BEH C18 column (3.5 $\mu \mathrm{m}, 3.0 \times 150 \mathrm{~mm}$, Waters Corporation) and a linear gradient from 3\% to 40\% solvent B over $18 \mathrm{~min}$ followed by an increase to $100 \% \mathrm{~B}$ over $5 \mathrm{~min}$ and $100 \% \mathrm{~B}$ for $5 \mathrm{~min}$ at a flow of 400 $\mu \mathrm{L} / \mathrm{min}$. Solvent A was $10 \mathrm{mM}$ ammonium formate buffer at $\mathrm{pH} 10.00$ and solvent $\mathrm{B}$ was $90 \%$ acetonitrile, $10 \% 10 \mathrm{mM}$ ammonium formate at $\mathrm{pH} 10$. The fractions were concatenated into 20 fractions, dried and reconstituted in 3\% acetonitrile, $0.2 \%$ formic acid.

nLC-MS/MS: The fractions were analyzed on an orbitrap Fusion Lumos Tribrid mass spectrometer interfaced with Easy-nLC1200 liquid chromatography system (Thermo Scientific). Peptides were trapped on an Acclaim Pepmap 100 C18 trap column (100 $\mu \mathrm{m}$ x 2 $\mathrm{cm}$, particle size $5 \mu \mathrm{m}$, Thermo Scientific) and separated on an in-house packed analytical column (75 $\mu \mathrm{m}$ x $35 \mathrm{~cm}$, particle size $3 \mu \mathrm{m}$, Reprosil-Pur C18, Dr. Maisch) using a gradient from $5 \%$ to $12 \%$ B over $5 \mathrm{~min}, 12 \%$ to $35 \%$ B over 72 min followed by an increase to $100 \% \mathrm{~B}$ for $3 \mathrm{~min}$, and $100 \% \mathrm{~B}$ for $10 \mathrm{~min}$ at a flow of $300 \mathrm{~nL} / \mathrm{min}$. Solvent A was $0.2 \%$ formic acid and solvent B was $80 \%$ acetonitrile, $0.2 \%$ formic acid. MS scans were performed at 120000 resolution, $m / z$ range $375-1375$. MS/MS analysis was performed in a data-dependent, with top speed cycle of $3 \mathrm{~s}$ for the most intense doubly or multiply charged precursor ions. Precursor ions were isolated in the quadrupole with a $0.7 \mathrm{~m} / \mathrm{z}$ isolation window, with dynamic exclusion set to $10 \mathrm{ppm}$ and duration of $45 \mathrm{~s}$. Isolated precursor ions were subjected to collision induced dissociation at 35 collision energy with a maximum injection time of $50 \mathrm{~ms}$. Produced MS2 fragment ions were detected in the ion trap followed by multinotch (simultaneous) isolation of the top 10 most abundant fragment ions for further fragmentation (MS3) by higher-energy collision dissociation (HCD) at $65 \%$ and detection in the Orbitrap at 50000 resolutions, $\mathrm{m} / \mathrm{z}$ range 100-500.

Proteomic Data Analysis: The data files were merged for identification and relative quantification using Proteome Discoverer v.2.4 (Thermo Scientific). Swiss-Prot Mus musculus database was used for the database search, using the Mascot search engine v.2.5.1 (Matrix Science) with MS peptide tolerance of $5 \mathrm{ppm}$ and fragment ion tolerance of $0.5 \mathrm{Da}$. Tryptic peptides were accepted with 0 missed cleavage and methionine oxidation was set as a variable modification. Cysteine methylthiolation and TMT on peptide N-termini and on lysine side chains were set as fixed modifications. Percolator was used for PSM validation with the strict FDR threshold of 1\%. Quantification was performed in Proteome Discoverer 2.4. The TMT reporter ions were identified with 3 mmu mass tolerance in the MS3 HCD spectra and the TMT reporter $\mathrm{S} / \mathrm{N}$ values for each sample were normalized within Proteome Discoverer 2.4 on the total peptide amount. Only the quantitative results for the unique peptide sequences with the minimum SPS match \% of 65 and the average S/N above 10 were taken into account for the protein quantification. Peptides were filtered for high confidence. Qlucore Omics Explorer 
software was used for the multivariant analysis. The complete lipid composition data are provided in supplementary tables.

\section{Laurdan Dye Measurement of Membrane Packing (Confocal Microscopy)}

Live cells were stained with Laurdan dye (6-dodecanoyl-2-dimethylaminonaphthalene) (Thermo Scientific) at $15 \mu \mathrm{M}$ for 45 min. MEFs, HEK293, INS-1E and U-2 OS cells were analyzed by confocal microscopy as previously (Ruiz et al., 2021; Ruiz et al., 2019). Images were acquired with an LSM880 confocal microscope equipped with a live cell chamber (set at $37^{\circ} \mathrm{C}$ and $5 \% \mathrm{CO}_{2}$ ) and $\mathrm{ZEN}$ software with a $40 \mathrm{X}$ water-immersion objective. Cells were excited with a $405 \mathrm{~nm}$ laser, and the emission was recorded between 410 and $461 \mathrm{~nm}$ (ordered phase) and between 470 and $530 \mathrm{~nm}$ (disordered phase). Pictures were acquired with 16-bit image depth and 1,024 x 1,024 resolution using a pixel dwell of $\sim 1.02 \mu \mathrm{s}$. Images were analyzed using ImageJ version 1.47 software (Schneider et al., 2012) following published guidelines (Owen et al., 2011).

\section{Laurdan Dye Measurement of Membrane Packing (Flow Cytometry)}

Live Jurkat E6.1 cells were stained with Laurdan dye as detailed above and analyzed by flow cytometry using a Cytoflex S (Beckman Coulter). Cells were resuspended in HBSS without $\mathrm{Ca}^{2+}$ and $\mathrm{Mg}^{2+}$ (Gibco) at $\mathrm{pH} 7.4$ supplemented with $10 \mathrm{mM}$ HEPES. Cells were excited with the UV laser $(405 \mathrm{~nm})$ and the emission was read with the fluorescent channel 450/45 BP for the ordered phase and with the 525/40 BP for the disordered phase. Data were analyzed with the Kaluza software (Beckman Coulter) version 2.1.

\section{Other Fluorescent Microscopy in MEFs}

AdipoR2-KO MEFs were treated with PA $200 \mu \mathrm{M}$ and then stained with BODIPY 500/510 C1, C12 (4,4-Difluoro- 5-Methyl-4-Bora-3a,4a-Diaza-s-Indacene-3-Dodecanoic Acid) (Invitrogen) at $2 \mathrm{mg} / \mathrm{ml}$ in PBS for $10 \mathrm{~min}$ or with Laurdan (see above) \pm ER-Tracker ${ }^{\text {TM }}$ Red (BODIPYTM TR Glibenclamide) (Thermo Scientific) at $0.5 \mu \mathrm{M}$. Z-stacks were acquired with an LSM880 confocal microscope equipped with a live cell chamber (set at $37^{\circ} \mathrm{C}$ and $5 \% \mathrm{CO} 2$ ) and ZEN software (Zeiss) with a $40 \mathrm{X}$ water objective. 2.5D image reconstructions containing spatial information were made using the temporal color code tool in ImageJ (Schneider et al., 2012).

\section{Fluorescence Recovery After Photobleaching (FRAP) in HEK293 Cells}

For FRAP in mammalian cells, HEK293 and INS-1E cells were stained with BODIPY 500/510 $\mathrm{C} 1, \mathrm{C} 12$ at $2 \mathrm{mg} / \mathrm{ml}$ in PBS for $10 \mathrm{~min}$ at $37^{\circ} \mathrm{C}$ (Devkota et al., 2017; Ruiz et al., 2019). FRAP images were acquired with an LSM880 confocal microscope equipped with a live cell chamber (set at $37^{\circ} \mathrm{C}$ and $5 \% \mathrm{CO}_{2}$ ) and $\mathrm{ZEN}$ software (Zeiss) with a $40 \mathrm{X}$ water immersion objective. Cells were excited with a $488 \mathrm{~nm}$ laser and the emission between 493 and $589 \mathrm{~nm}$ recorded. Images were acquired with 16 bits image depth and $256 \times 256$ resolution using a pixel dwell of $\sim 1.34 \mu \mathrm{s}$. Ten pre-bleaching images were collected and then the region of interest was beached with $50 \%$ of laser power. The recovery of fluorescence was traced for $25 \mathrm{~s}$. Fluorescence recovery and $\mathrm{T}_{\text {half }}(50 \%$ intensity of the fluorescence recovered) were calculated as previously described (Devkota et al., 2017). 


\section{FRAP in C. elegans}

FRAP experiments in C. elegans were carried out using a membrane-associated prenylated GFP reporter expressed in intestinal cells and using a Zeiss LSM700 inv laser scanning confocal microscope with a $40 \mathrm{X}$ water immersion objective. Briefly, the GFP-positive membranes were photobleached over a rectangular area ( $15 \times 4$ pixels $)$ using 30 iterations of the $488 \mathrm{~nm}$ laser with $50 \%$ laser power transmission. Images were collected at a 12-bit intensity resolution over $256 \times 256$ pixels (digital zoom 4 X) using a pixel dwell time of $1.58 \mu \mathrm{s}$, and were all acquired under identical settings. The recovery of fluorescence was traced for $25 \mathrm{~s}$. Fluorescence recovery and $T_{\text {half }}$ were calculated (Devkota and Pilon, 2018).

\section{Quantitative PCR (qPCR)}

Total cellular/worm RNA was isolated using RNeasy Plus Kit according to the manufacturer's instructions (Qiagen) and quantified using a NanoDrop spectrophotometer (ND-1000; Thermo Scientific). cDNA was obtained using a RevertAid H Minus First Strand cDNA Synthesis Kit (Thermo Scientific) with random hexamers. qPCR was performed with a CFX Connect thermal cycler (Bio-Rad) using HOT FIREpol EvaGreen qPCR Supermix (Solis Biodyne) and standard primers (see the primer list below, some primers were previously described in (Bjursell et al., 2007; Devkota et al., 2017; Gomez and Rutkowski, 2016; Ruiz et al., 2021; Rutkowski et al., 2006; Zhang et al., 2012) as indicated in the table). Samples were measured as triplicates. The relative expression of each gene was calculated according to the delta-deltaCT method (Livak and Schmittgen, 2001). PPIA expression was used as calibrator in human and mouse experiments and tba- 1 in $C$. elegans.

\begin{tabular}{|c|c|c|c|}
\hline Sequence $\left(5^{\prime}-->3^{\prime}\right)$ & Organism & Purpose - Target & Reference \\
\hline $\begin{array}{l}\text { AGGCAGGGTAAGCTGATTAGCTATG } \\
\text { TCCACTGTGTCAGCTTCTCTGTTAC } \\
\text { GGGTGGGATTAGATAAATGCCTGCTCT }\end{array}$ & $\begin{array}{l}\text { Mus } \\
\text { musculus }\end{array}$ & $\begin{array}{l}\text { Genotyping - } \\
\text { Adipor1 }\end{array}$ & $\begin{array}{l}\text { (Bjursell et al., } \\
2007 \text { ) }\end{array}$ \\
\hline $\begin{array}{l}\text { GACGGAGTTTGTATGTGGTAGCGTC } \\
\text { TCTCTGCCTTTCCTTTTCATGGCTC } \\
\text { GGGCCAGCTCATTCCTCCCACTCAT }\end{array}$ & $\begin{array}{l}\text { Mus } \\
\text { musculus }\end{array}$ & $\begin{array}{l}\text { Genotyping / } \\
\text { Adipor2 }\end{array}$ & $\begin{array}{l}\text { (Bjursell et al., } \\
2007 \text { ) }\end{array}$ \\
\hline $\begin{array}{l}\text { CTGCCTTTCACCTTGGAGAC } \\
\text { CGTTTCCTGGGGATGAGATA }\end{array}$ & $\begin{array}{l}\text { Mus } \\
\text { musculus }\end{array}$ & qPCR - Ddit3 & $\begin{array}{l}\text { (Rutkowski et al., } \\
2006 \text { ) }\end{array}$ \\
\hline $\begin{array}{l}\text { CATGGTTCTCACTAAAATGAAAGG } \\
\text { GCTGGTACAGTAACAACTG }\end{array}$ & $\begin{array}{l}\text { Mus } \\
\text { musculus }\end{array}$ & qPCR - Hspa5 & $\begin{array}{l}\text { (Rutkowski et al., } \\
2006 \text { ) }\end{array}$ \\
\hline $\begin{array}{l}\text { ATGGCCGGCTATGGATGAT } \\
\text { CGAAGTCAAACTCTTTCAGATCCATT }\end{array}$ & $\begin{array}{l}\text { Mus } \\
\text { musculus }\end{array}$ & $\mathrm{qPCR}-$ Atf4 & $\begin{array}{l}\text { (Rutkowski et al., } \\
2006 \text { ) }\end{array}$ \\
\hline $\begin{array}{l}\text { GAGTCCGCAGCAGGTG } \\
\text { TAAGACTCCTGCCTGACTGC }\end{array}$ & $\begin{array}{l}\text { Mus } \\
\text { musculus }\end{array}$ & $\mathrm{qPCR}-s X B P 1$ & $\begin{array}{l}\text { (Gomez and } \\
\text { Rutkowski, 2016) }\end{array}$ \\
\hline $\begin{array}{l}\text { ACTACACAACGGGAGCAACAG } \\
\text { GATGGAAAGCAGGAGCAGAG }\end{array}$ & $\begin{array}{l}\text { Mus } \\
\text { musculus }\end{array}$ & qPCR - Slpr1 & (Zhang et al., 2012) \\
\hline CTCACTGCTCAATCCTGTCATC & & $\mathrm{qPCR}-$ S1pr2 & $\overline{\text { (Zhang et al., 2012) }}$ \\
\hline
\end{tabular}




\begin{tabular}{|c|c|c|c|}
\hline TTCACATTTTCCCTTCAGACC & $\begin{array}{l}\text { Mus } \\
\text { musculus }\end{array}$ & & \\
\hline $\begin{array}{l}\text { TTCCCGACTGCTCTACCATC } \\
\text { CCAACAGGCAATGAACACAC }\end{array}$ & $\begin{array}{l}\text { Mus } \\
\text { musculus }\end{array}$ & $\mathrm{qPCR}-$ S1pr3 & (Zhang et al., 2012) \\
\hline $\begin{array}{l}\text { TGCGGGTGGCTGAGAGTG } \\
\text { TAGGATCAGGGCGAAGACC }\end{array}$ & $\begin{array}{l}\text { Mus } \\
\text { musculus }\end{array}$ & $\mathrm{qPCR}-$ S1pr4 & (Zhang et al., 2012) \\
\hline $\begin{array}{l}\text { CTTAGGACGCCTGGAAACC } \\
\text { CCCGCACCTGACAGTAAATC }\end{array}$ & $\begin{array}{l}\text { Mus } \\
\text { musculus }\end{array}$ & qPCR - S1pr5 & (Zhang et al., 2012) \\
\hline $\begin{array}{l}\text { GTCTCCTTCGAGCTGTTTGC } \\
\text { GCGTGTAAAGTCACCACCCT }\end{array}$ & $\begin{array}{l}\text { Mus } \\
\text { musculus }\end{array}$ & $\begin{array}{l}\text { qPCR - PPIA } \\
\text { (housekeeping) }\end{array}$ & This study \\
\hline $\begin{array}{l}\text { TGACCAACAAGGAGATGCGT } \\
\text { AATTGTCCGATTTGCTGCGG }\end{array}$ & $\begin{array}{l}\text { Homo } \\
\text { sapiens }\end{array}$ & qPCR - S1PRI & This study \\
\hline $\begin{array}{l}\text { GCCTCTCTACGCCAAGCATT } \\
\text { GCAGCCAGCAGACGATAAAG }\end{array}$ & $\begin{array}{l}\text { Homo } \\
\text { sapiens }\end{array}$ & qPCR - S1PR2 & This study \\
\hline $\begin{array}{l}\text { TGAAGTCCAGCAGCCGTAAG } \\
\text { AGCCAACACGATGAACCACT }\end{array}$ & $\begin{array}{l}\text { Homo } \\
\text { sapiens }\end{array}$ & qPCR - S1PR3 & This study \\
\hline $\begin{array}{l}\text { CATCATGGGCCTCTATGGGG } \\
\text { AGAGGTTGGAGCCAAAGACG }\end{array}$ & $\begin{array}{l}\text { Homo } \\
\text { sapiens }\end{array}$ & qPCR - S1PR4 & This study \\
\hline $\begin{array}{l}\text { CTTTGTGGCATGTTGGGGC } \\
\text { GCGTGTAGATGATGGGGTTCA }\end{array}$ & $\begin{array}{l}\text { Homo } \\
\text { sapiens }\end{array}$ & qPCR - S1PR5 & This study \\
\hline $\begin{array}{l}\text { GACTGCCTGATTGACAAGCG } \\
\text { ATTCTCGTTCCGGTCCTTGC }\end{array}$ & $\begin{array}{l}\text { Homo } \\
\text { sapiens }\end{array}$ & $\mathrm{qPCR}-R X R A$ & This study \\
\hline $\begin{array}{l}\text { ATGCTGGCTATGAGCAGGTC } \\
\text { CCCAGACGCCGATACTTCTC }\end{array}$ & $\begin{array}{l}\text { Homo } \\
\text { sapiens }\end{array}$ & qPCR - Sphk1 & This study \\
\hline $\begin{array}{l}\text { CCCCGGTTGCTTCTATTGGT } \\
\text { GATCTAGGAGCCCGTTCAGC }\end{array}$ & $\begin{array}{l}\text { Homo } \\
\text { sapiens }\end{array}$ & qPCR - Sphk2 & This study \\
\hline $\begin{array}{l}\text { GACCAAAGCAAAGGCGAGGG } \\
\text { CAGCCCTGAAAGATGCGGATG }\end{array}$ & $\begin{array}{l}\text { Homo } \\
\text { sapiens }\end{array}$ & $\mathrm{qPCR}-P P A R G$ & This study \\
\hline $\begin{array}{l}\text { GCGAACGATTCGACTCAAGC } \\
\text { TCGTCCAAAACGAATCGCGT }\end{array}$ & $\begin{array}{l}\text { Homo } \\
\text { sapiens }\end{array}$ & $\mathrm{qPCR}-P P A R A$ & This study \\
\hline $\begin{array}{l}\text { GTCTCCTTTGAGCTGTTTGCAG } \\
\text { GGACAAGATGCCAGGACCC }\end{array}$ & $\begin{array}{l}\text { Homo } \\
\text { sapiens }\end{array}$ & $\begin{array}{l}\text { qPCR - PPIA } \\
\text { (housekeeping) }\end{array}$ & $\begin{array}{l}\text { (Devkota et al., } \\
\text { 2017) }\end{array}$ \\
\hline $\begin{array}{l}\text { GACCTCGCAGATCCAGCAG } \\
\text { ATAGGCAGCTTCTCCGCATC }\end{array}$ & $\begin{array}{l}\text { Homo } \\
\text { sapiens }\end{array}$ & qPCR - SREBF1 & (Ruiz et al., 2021) \\
\hline $\begin{array}{l}\text { GTGCTGTTCCTGACTCCCTG } \\
\text { CAGCCTTCTTCTTGGCCTGA }\end{array}$ & $\begin{array}{l}\text { Homo } \\
\text { sapiens }\end{array}$ & $\mathrm{qPCR}-S R E B F 2$ & (Ruiz et al., 2021) \\
\hline $\begin{array}{l}\text { TTCGTTGCCACTTTCTTGCG } \\
\text { TGGTGGTAGTTGTGGAAGCC }\end{array}$ & $\begin{array}{l}\text { Homo } \\
\text { sapiens }\end{array}$ & $\mathrm{qPCR}-S C D$ & $\begin{array}{l}\text { (Devkota et al., } \\
\text { 2017) }\end{array}$ \\
\hline $\begin{array}{l}\text { CCATCTGCTTGGTTTCGTGC } \\
\text { AGACGGTGTGAAAGAGCCAG }\end{array}$ & $\begin{array}{l}\text { Homo } \\
\text { sapiens }\end{array}$ & qPCR - AdipoRl & $\begin{array}{l}\text { (Devkota et al., } \\
\text { 2017) }\end{array}$ \\
\hline TCATCTGTGTGCTGGGCATT & & qPCR - AdipoR2 & \\
\hline
\end{tabular}




\begin{tabular}{|c|c|c|c|}
\hline СTATCTGCCCTATGGTGGCG & $\begin{array}{l}\text { Homo } \\
\text { sapiens }\end{array}$ & & $\begin{array}{l}\text { (Devkota et al. } \\
\text { 2017) }\end{array}$ \\
\hline $\begin{array}{l}\text { TCTCGCAGGTTGTGTCTTCC } \\
\text { AGCCTCATGGTAAGCCTTGT }\end{array}$ & C. elegans & $\begin{array}{l}\text { qPCR - } t b a- \\
1 \text { (housekeeping) }\end{array}$ & This study \\
\hline $\begin{array}{l}\text { CAGTTGGATGGGTATTCCTCCT } \\
\text { TCCATGAGAGGGTGGCTTTG }\end{array}$ & C. elegans & qPCR - fat -5 & This study \\
\hline $\begin{array}{l}\text { GACCCAGTTCTCGTCTTCCA } \\
\text { ATCCGAAATAGTGAGCAGCG }\end{array}$ & C. elegans & qPCR - fat-6 & This study \\
\hline $\begin{array}{l}\text { GCCGTCTTCTCATTTGCTCTC } \\
\text { ACGATGATCACGAGCCCATT }\end{array}$ & C. elegans & qPCR - fat-7 & This study \\
\hline
\end{tabular}

\section{Protein Extraction and Western-blot (HEK293 cells)}

Cellular proteins were extracted using "Lola's" lysis buffer (1\% Nonidet P-40, 0.1\% SDS, 10\% glycerol, $1 \%$ sodium deoxycholate, 1 mM DTT, 1 mM EDTA, $100 \mathrm{mM}$ HEPES, $100 \mathrm{mM} \mathrm{KCl}$ ) containing Halt Protease Inhibitor Cocktail (1X; Pierce) on ice for 10 min. Upon lysis completion, cell lysates were centrifuged at $13000 \mathrm{rpm}$ for $10 \mathrm{~min}$ at $4{ }^{\circ} \mathrm{C}$. The soluble fraction was kept for further analysis, and the protein sample concentration was quantified using the BCA protein assay kit (Pierce) according to the manufacturer's instructions. Twenty (HA blot) or forty (SREBP1 blot) micrograms of protein were mixed with Laemmli sample loading buffer (Bio-Rad), heated to $37^{\circ} \mathrm{C}$ for $10 \mathrm{~min}$, and loaded in $4 \%$ to $20 \%$ gradient precast SDS gels (Bio$\mathrm{Rad})$. After electrophoresis, the proteins were transferred to nitrocellulose membranes using Trans-Blot Turbo Transfer Packs and a Trans-Blot Turbo apparatus/predefined mixed-MW program (Bio-Rad). Blots were blocked with 5\% nonfat dry milk (HA blot) or EveryBlot Blocking Buffer (Bio-Rad) (SREBP1 blot) in PBS-T for $1 \mathrm{~h}$ at room temperature. Blots were incubated with primary antibodies overnight at $4{ }^{\circ} \mathrm{C}$ : rabbit monoclonal anti-HA antibody (C29F4, Cell signaling) 1:5000 dilution, mouse monoclonal anti-SREBP1 (2A4, Santa Cruz) 1:200 or mouse monoclonal anti-Tubulin (B512, Sigma) 1:5000. Blots were then washed with PBS-T and incubated with either swine anti-rabbit HRP (1:3000, Dako) or goat anti-mouse $\operatorname{HRP}(1: 3000$, Dako) and washed again with PBS-T. Detection of the hybridized antibody was performed using an ECL detection kit (Immobilon Western, Millipore), and the signal was visualized with a digital camera (VersaDoc, Bio-Rad). Signal intensities were quantified using Image Lab Software (Bio-Rad).

\section{Glucose Stimulated Insulin Secretion (GSIS)}

INS-1E cells were cultivated overnight in serum-free medium $\pm \mathrm{PA} 400 \mu \mathrm{M} \pm \mathrm{S} 1 \mathrm{P}$, washed with Hanks' Balanced Salt Solution (HBSS) without $\mathrm{Ca}^{+2}$ and $\mathrm{Mg}^{+2}$ and maintained in HBSS without glucose for $2 \mathrm{~h}$. Then, the cells were stimulated with HBSS with glucose $16 \mathrm{mM}$ for $30 \mathrm{~min}$ and the supernatant later collected. The amount of insulin secreted was quantified using a Rat Insulin ELISA (Mercodia) following manufacture instructions.

\section{Plasmids for HEK293 cells and Transfection}

pIREShyg2-HA-hAdipoR2-cMYC construct was described in (Busayavalasa et al., 2020). pIREShyg2-HA-hAdipoR2-cMYC(H348A) construct was generated using PCR-based mutagenesis (Q5-site-directed mutagenesis kit, New England Biolabs) with the following 
primers: 5'-gctcagctgtttcatatctttg-3' and 5'-agagtgaaaccagatgtcac-3'.

pIREShyg2-HAhAdipoR2-cMYC(H202A, H348A, H352A) construct was generated using Gibson-assembly cloning kit (NEB) with the following primers: 5'-ttttcatggctcttcgecacagtctactgccactcagagg-3' and 5 '-agcaaacagctgagcagagtgaaaccagatgtcacatttg-3' for amplification of the fragment generating H348A and H352A mutations; 5'-tctgctcagctgtttgctatctttgtggttgctggagc-3' and 5'ggcgaagagccatgaaaaagaaaggcagagaatggctcct-3' for amplification of the fragment generating H202A mutation and the rest of the vector sequence. HEK293 cells were transfected using Viromer Red according to the manufacturer's instructions 1X protocol (Lipocalyx) and the protein expression verified by Western-blot $24 \mathrm{~h}$ after transfection.

\section{Plasmids for $C$. elegans and Injections}

Wild-type PAQR-2::GFP( $p P A Q R-2: \because N-G F P)$ construct have been described elsewhere (Svensson et al., 2011). PAQR-2::GFP(H511A) construct was generated using PCR-based mutagenesis (Q5-site-directed mutagenesis kit, New England Biolabs) with the following primers: 5'- gctcaactctttcacacatttg-3' and 5'-cgattggaactgaaaaaataaacg-3'. PAQR$2:: \mathrm{GFP}(\mathrm{H} 365 \mathrm{~A}, \mathrm{H} 511 \mathrm{~A}, \mathrm{H} 515 \mathrm{~A})$ construct was generated from PAQR-2::GFP(pPAQR-2::NGFP) using gibson-assembly cloning kit (NEB) with the following primers: 5'gctacggttgcatgccattctattgaaatggctaaactgt-3' and 5'gtggcaaagagttgagccgattggaactgaaaaaataaacgt-3' for amplification of the fragment generating H365A and H511A mutations; 5'-tcggctcaactctttgccacatttgtcgtgctcgecgc-3' and 5'atggcatgcaaccgtagcaaaaaggaatgacattccaaga-3' for amplification of the fragment generating $\mathrm{H} 365 \mathrm{~A}$ mutation and the rest of the vector sequence. Constructs were injected into N2 worms at $25 \mathrm{ng} / \mu \mathrm{l}$ together with $40 \mathrm{ng} / \mu \mathrm{l} p R F 4$, which carries the dominant rol-6(su1006) marker used to identify transgenic worms (Mello et al., 1991).

\section{C. elegans Growth}

For length measurement studies, synchronized L1s were plated onto test plates seeded with $E$. coli, and worms were mounted and photographed $144 \mathrm{~h}\left(15^{\circ} \mathrm{C}\right.$ experiments) or $72 \mathrm{~h}$ (all other experiments) later. The length of 20 worms were measured using ImageJ (Schneider et al., 2012). Alternatively, the stages of the worms (L1, L2-3, L4 or adult, $n=50$ ).

\section{Quantification of Tail Tip Morphology in C. elegans}

Quantification of the withered tail tip phenotype was done on synchronous 1 day old adult populations, that is $72 \mathrm{~h}$ post $\mathrm{L} 1$ ( $\mathrm{n} \geq 50$ ) (Svensk et al., 2013).

\section{C. elegans FAT-7 Expression}

Quantification of fluorescence intensity of $p f a t-7:: G F P$ carrying strains were performed on L4 larvae using ImageJ ( $\mathrm{n} \geq 20)$ (Svensk et al., 2013).

\section{Statistics}

Error bars show the standard error of the mean, and t-tests were used to identify significant differences between treatments (except in qPCR panels, where error bars show standard error). For the lipidomics and proteomics analysis, ANOVA was used to identify lipids that were significantly different among the groups. For electron microscopy experiments, an exact 
binomial test was performed with a hypothesized probability of success equal to the frequency of the respective control group. The test was performed using the $\mathrm{R}$ package (R Core Team, 2018). In the box plots, boxes indicate the $25^{\text {th }}$ to $75^{\text {th }}$ percentile while the whiskers indicate the data points still within 1.5 of the box range. Asterisks are used in the figures to indicate various degrees of significance, where $*$ : $p<0.05 ; * *$ : $<<0.01$; and $* * *: p<0.001$.

\section{SUPPLEMENTAL INFORMATION}

Supplemental Information includes 7 supplementary figures and 7 supplementary tables and can be found with this article online.

Table S1. Mouse Embryo Genotypes. Related to figure 1 and S1.

Table S2. Mouse Embryo Lipidomics. Related to figure 1 and S1.

Table S3. Mouse Embryo Proteomics. Related to figure 1 and S1.

Table S4. MEFs Lipidomics. Related to figure 2 and S2.

Table S5. HEK293 cells Lipidomics. Related to figure 3, 5, 7, S3, S4 and S7.

Table S6. Other assays. Related to figure 3-7, S4 and S6.

Table S7. C. elegans Lipidomics. Related to figure 7.

\section{REFERENCES}

Amrutkar, M., Cansby, E., Nunez-Duran, E., Pirazzi, C., Stahlman, M., Stenfeldt, E., Smith, U., Boren, J., and Mahlapuu, M. (2015). Protein kinase STK25 regulates hepatic lipid partitioning and progression of liver steatosis and NASH. FASEB J 29, 1564-1576.

Bakan, E., Yildirim, A., Kurtul, N., Polat, M.F., Dursun, H., and Cayir, K. (2006). Effects of type 2 diabetes mellitus on plasma fatty acid composition and cholesterol content of erythrocyte and leukocyte membranes. Acta Diabetol 43, 109-113.

Barak, Y., Nelson, M.C., Ong, E.S., Jones, Y.Z., Ruiz-Lozano, P., Chien, K.R., Koder, A., and Evans, R.M. (1999). PPAR gamma is required for placental, cardiac, and adipose tissue development. Mol Cell 4, 585-595.

Bjursell, M., Ahnmark, A., Bohlooly, Y.M., William-Olsson, L., Rhedin, M., Peng, X.R., Ploj, K., Gerdin, A.K., Arnerup, G., Elmgren, A., et al. (2007). Opposing effects of adiponectin receptors 1 and 2 on energy metabolism. Diabetes 56, 583-593.

Blaho, V.A., and Hla, T. (2014). An update on the biology of sphingosine 1-phosphate receptors. J Lipid Res 55, 1596-1608.

Bodhicharla, R., Devkota, R., Ruiz, M., and Pilon, M. (2018). Membrane Fluidity Is Regulated Cell Nonautonomously by Caenorhabditis elegans PAQR-2 and Its Mammalian Homolog AdipoR2. Genetics 210, 189-201.

Borradaile, N.M., Han, X., Harp, J.D., Gale, S.E., Ory, D.S., and Schaffer, J.E. (2006). Disruption of endoplasmic reticulum structure and integrity in lipotoxic cell death. J Lipid Res 47, 2726-2737.

Botta, A., Elizbaryan, K., Tashakorinia, P., Lam, N.H., and Sweeney, G. (2020). An adiponectin-S1P autocrine axis protects skeletal muscle cells from palmitate-induced cell death. Lipids Health Dis 19, 156.

Brenner, S. (1974). The genetics of Caenorhabditis elegans. Genetics 77, 71-94.

Busayavalasa, K., Ruiz, M., Devkota, R., Stahlman, M., Bodhicharla, R., Svensk, E., Hermansson, N.O., Boren, J., and Pilon, M. (2020). Leveraging a gain-of-function allele of Caenorhabditis elegans paqr-1 to elucidate membrane homeostasis by PAQR proteins. PLoS Genet 16, e1008975. 
Chakraborty, P., Vaena, S.G., Thyagarajan, K., Chatterjee, S., Al-Khami, A., Selvam, S.P., Nguyen, H., Kang, I., Wyatt, M.W., Baliga, U., et al. (2019). Pro-Survival Lipid Sphingosine1-Phosphate Metabolically Programs T Cells to Limit Anti-tumor Activity. Cell Rep 28, 18791893 e1877.

Devkota, R., Henricsson, M., Boren, J., and Pilon, M. (2021a). The C. elegans PAQR-2 and IGLR-2 membrane homeostasis proteins are uniquely essential for tolerating dietary saturated fats. Biochim Biophys Acta Mol Cell Biol Lipids 1866, 158883.

Devkota, R., Kaper, D., Bodhicharla, R., Henricsson, M., Boren, J., and Pilon, M. (2021b). A Genetic Titration of Membrane Composition in C. elegans Reveals its Importance for Multiple Cellular and Physiological Traits. Genetics.

Devkota, R., and Pilon, M. (2018). FRAP: A Powerful Method to Evaluate Membrane Fluidity in Caenorhabditis elegans Bio-protocols 8 .

Devkota, R., Svensk, E., Ruiz, M., Stahlman, M., Boren, J., and Pilon, M. (2017). The adiponectin receptor AdipoR2 and its Caenorhabditis elegans homolog PAQR-2 prevent membrane rigidification by exogenous saturated fatty acids. PLoS Genet 13, e1007004.

Eberle, D., Hegarty, B., Bossard, P., Ferre, P., and Foufelle, F. (2004). SREBP transcription factors: master regulators of lipid homeostasis. Biochimie 86, 839-848.

Ejsing, C.S., Sampaio, J.L., Surendranath, V., Duchoslav, E., Ekroos, K., Klemm, R.W., Simons, K., and Shevchenko, A. (2009). Global analysis of the yeast lipidome by quantitative shotgun mass spectrometry. Proc Natl Acad Sci U S A 106, 2136-2141.

Ekroos, K., Ejsing, C.S., Bahr, U., Karas, M., Simons, K., and Shevchenko, A. (2003). Charting molecular composition of phosphatidylcholines by fatty acid scanning and ion trap MS3 fragmentation. J Lipid Res 44, 2181-2192.

Farese, R.V., Jr., Ruland, S.L., Flynn, L.M., Stokowski, R.P., and Young, S.G. (1995). Knockout of the mouse apolipoprotein B gene results in embryonic lethality in homozygotes and protection against diet-induced hypercholesterolemia in heterozygotes. Proc Natl Acad Sci U S A 92, 1774-1778.

Gomez, J.A., and Rutkowski, D.T. (2016). Experimental reconstitution of chronic ER stress in the liver reveals feedback suppression of BiP mRNA expression. Elife 5.

Green, C.D., Maceyka, M., Cowart, L.A., and Spiegel, S. (2021). Sphingolipids in metabolic disease: The good, the bad, and the unknown. Cell Metab 33, 1293-1306.

Hait, N.C., Allegood, J., Maceyka, M., Strub, G.M., Harikumar, K.B., Singh, S.K., Luo, C., Marmorstein, R., Kordula, T., Milstien, S., et al. (2009). Regulation of histone acetylation in the nucleus by sphingosine-1-phosphate. Science 325, 1254-1257.

Hastoy, B., Clark, A., Rorsman, P., and Lang, J. (2017). Fusion pore in exocytosis: More than an exit gate? A beta-cell perspective. Cell Calcium 68, 45-61.

Hawes, P., Netherton, C.L., Mueller, M., Wileman, T., and Monaghan, P. (2007). Rapid freezesubstitution preserves membranes in high-pressure frozen tissue culture cells. J Microsc 226, 182-189.

Holland, W.L., Miller, R.A., Wang, Z.V., Sun, K., Barth, B.M., Bui, H.H., Davis, K.E., Bikman, B.T., Halberg, N., Rutkowski, J.M., et al. (2011). Receptor-mediated activation of ceramidase activity initiates the pleiotropic actions of adiponectin. Nat Med 17, 55-63.

Holland, W.L., Xia, J.Y., Johnson, J.A., Sun, K., Pearson, M.J., Sharma, A.X., Quittner-Strom, E., Tippetts, T.S., Gordillo, R., and Scherer, P.E. (2017). Inducible overexpression of adiponectin receptors highlight the roles of adiponectin-induced ceramidase signaling in lipid and glucose homeostasis. Mol Metab 6, 267-275.

Homan, R., and Anderson, M.K. (1998). Rapid separation and quantitation of combined neutral and polar lipid classes by high-performance liquid chromatography and evaporative lightscattering mass detection. J Chromatogr B Biomed Sci Appl 708, 21-26. 
Horton, J.D., Goldstein, J.L., and Brown, M.S. (2002). SREBPs: activators of the complete program of cholesterol and fatty acid synthesis in the liver. J Clin Invest 109, 1125-1131.

Iwabu, M., Okada-Iwabu, M., Tanabe, H., Ohuchi, N., Miyata, K., Kobori, T., Odawara, S., Kadowaki, Y., Yokoyama, S., Yamauchi, T., et al. (2021). AdipoR agonist increases insulin sensitivity and exercise endurance in AdipoR-humanized mice. Commun Biol 4, 45.

Jung, H.R., Sylvanne, T., Koistinen, K.M., Tarasov, K., Kauhanen, D., and Ekroos, K. (2011). High throughput quantitative molecular lipidomics. Biochim Biophys Acta 1811, 925-934.

Kremer, J.R., Mastronarde, D.N., and McIntosh, J.R. (1996). Computer visualization of threedimensional image data using IMOD. J Struct Biol 116, 71-76.

Krogh, A., Larsson, B., von Heijne, G., and Sonnhammer, E.L. (2001). Predicting transmembrane protein topology with a hidden Markov model: application to complete genomes. J Mol Biol 305, 567-580.

Lee, K., Escobar, I., Jang, Y., Kim, W., Ausubel, F.M., and Mylonakis, E. (2020). In the Model Host Caenorhabditis elegans, Sphingosine-1-Phosphate-Mediated Signaling Increases Immunity toward Human Opportunistic Bacteria. Int J Mol Sci 21.

Lee, S.Y., Lee, H.Y., Song, J.H., Kim, G.T., Jeon, S., Song, Y.J., Lee, J.S., Hur, J.H., Oh, H.H., Park, S.Y., et al. (2017). Adipocyte-Specific Deficiency of De Novo Sphingolipid Biosynthesis Leads to Lipodystrophy and Insulin Resistance. Diabetes 66, 2596-2609.

Lindgren, A., Levin, M., Rodrigo Blomqvist, S., Wikstrom, J., Ahnmark, A., Mogensen, C., Bottcher, G., Bohlooly, Y.M., Boren, J., Gan, L.M., et al. (2013). Adiponectin receptor 2 deficiency results in reduced atherosclerosis in the brachiocephalic artery in apolipoprotein $\mathrm{E}$ deficient mice. PLoS One 8, e80330.

Listenberger, L.L., Han, X., Lewis, S.E., Cases, S., Farese, R.V., Jr., Ory, D.S., and Schaffer, J.E. (2003). Triglyceride accumulation protects against fatty acid-induced lipotoxicity. Proc Natl Acad Sci U S A 100, 3077-3082.

Liu, Y., Michael, M.D., Kash, S., Bensch, W.R., Monia, B.P., Murray, S.F., Otto, K.A., Syed, S.K., Bhanot, S., Sloop, K.W., et al. (2007). Deficiency of adiponectin receptor 2 reduces dietinduced insulin resistance but promotes type 2 diabetes. Endocrinology 148, 683-692.

Livak, K.J., and Schmittgen, T.D. (2001). Analysis of relative gene expression data using realtime quantitative PCR and the 2(-Delta Delta C(T)) Method. Methods 25, 402-408.

Lofgren, L., Forsberg, G.B., and Stahlman, M. (2016). The BUME method: a new rapid and simple chloroform-free method for total lipid extraction of animal tissue. Sci Rep 6, 27688.

McDonald, K., Schwarz, H., Muller-Reichert, T., Webb, R., Buser, C., and Morphew, M. (2010). "Tips and tricks" for high-pressure freezing of model systems. Methods Cell Biol 96, 671-693.

Mello, C.C., Kramer, J.M., Stinchcomb, D., and Ambros, V. (1991). Efficient gene transfer in C.elegans: extrachromosomal maintenance and integration of transforming sequences. EMBO J 10, 3959-3970.

Mendelson, K., Evans, T., and Hla, T. (2014). Sphingosine 1-phosphate signalling. Development 141, 5-9.

Mizugishi, K., Yamashita, T., Olivera, A., Miller, G.F., Spiegel, S., and Proia, R.L. (2005). Essential role for sphingosine kinases in neural and vascular development. Mol Cell Biol 25, 11113-11121.

Murphy, R.C., James, P.F., McAnoy, A.M., Krank, J., Duchoslav, E., and Barkley, R.M. (2007). Detection of the abundance of diacylglycerol and triacylglycerol molecular species in cells using neutral loss mass spectrometry. Anal Biochem 366, 59-70.

Onodera, T., Ghazvini Zadeh, E., Xu, P., Gordillo, R., Guo, Z., Joffin, N., Yu, B., Scherer, P.E., and Li, W.H. (2021). PEGylated AdipoRon derivatives improve glucose and lipid metabolism under insulinopenic and high-fat diet conditions. J Lipid Res 62, 100095. 
Osada, H., Toda, E., Homma, K., Guzman, N.A., Nagai, N., Ogawa, M., Negishi, K., Arita, M., Tsubota, K., and Ozawa, Y. (2021). ADIPOR1 deficiency-induced suppression of retinal ELOVL2 and docosahexaenoic acid levels during photoreceptor degeneration and visual loss. Cell Death Dis 12, 458.

Owen, D.M., Rentero, C., Magenau, A., Abu-Siniyeh, A., and Gaus, K. (2011). Quantitative imaging of membrane lipid order in cells and organisms. Nat Protoc 7, 24-35.

Panagaki, D., Croft, J.T., Keuenhof, K., Larsson Berglund, L., Andersson, S., Kohler, V., Buttner, S., Tamas, M.J., Nystrom, T., Neutze, R., et al. (2021). Nuclear envelope budding is a response to cellular stress. Proc Natl Acad Sci U S A 118.

Parham, K.A., Zebol, J.R., Tooley, K.L., Sun, W.Y., Moldenhauer, L.M., Cockshell, M.P., Gliddon, B.L., Moretti, P.A., Tigyi, G., Pitson, S.M., et al. (2015). Sphingosine 1-phosphate is a ligand for peroxisome proliferator-activated receptor-gamma that regulates neoangiogenesis. FASEB J 29, 3638-3653.

Piccolis, M., Bond, L.M., Kampmann, M., Pulimeno, P., Chitraju, C., Jayson, C.B.K., Vaites, L.P., Boland, S., Lai, Z.W., Gabriel, K.R., et al. (2019). Probing the Global Cellular Responses to Lipotoxicity Caused by Saturated Fatty Acids. Mol Cell 74, 32-44 e38.

Pilon, M. (2016). Revisiting the membrane-centric view of diabetes. Lipids Health Dis 15, 167. Pilon, M. (2021). Paradigm shift: the primary function of the "Adiponectin Receptors" is to regulate cell membrane composition. Lipids Health Dis 20, 43.

Porstmann, T., Santos, C.R., Griffiths, B., Cully, M., Wu, M., Leevers, S., Griffiths, J.R., Chung, Y.L., and Schulze, A. (2008). SREBP activity is regulated by mTORC1 and contributes to Akt-dependent cell growth. Cell Metab 8, 224-236.

Reynolds, E.S. (1963). The use of lead citrate at high $\mathrm{pH}$ as an electron-opaque stain in electron microscopy. J Cell Biol 17, 208-212.

Rice, D.S., Calandria, J.M., Gordon, W.C., Jun, B., Zhou, Y., Gelfman, C.M., Li, S., Jin, M., Knott, E.J., Chang, B., et al. (2015). Adiponectin receptor 1 conserves docosahexaenoic acid and promotes photoreceptor cell survival. Nat Commun 6, 6228.

Ruiz, M., Frej, C., Holmer, A., Guo, L.J., Tran, S., and Dahlback, B. (2017a). High-Density Lipoprotein-Associated Apolipoprotein M Limits Endothelial Inflammation by Delivering Sphingosine-1-Phosphate to the Sphingosine-1-Phosphate Receptor 1. Arterioscler Thromb Vasc Biol 37, 118-129.

Ruiz, M., Okada, H., and Dahlback, B. (2017b). HDL-associated ApoM is anti-apoptotic by delivering sphingosine 1-phosphate to S1P1 \& S1P3 receptors on vascular endothelium. Lipids Health Dis 16, 36.

Ruiz, M., Palmgren, H., Henricsson, M., Devkota, R., Jaiswal, H., Maresca, M., Bohlooly, Y.M., Peng, X.R., Boren, J., and Pilon, M. (2021). Extensive transcription mis-regulation and membrane defects in AdipoR2-deficient cells challenged with saturated fatty acids. Biochim Biophys Acta Mol Cell Biol Lipids 1866, 158884.

Ruiz, M., Stahlman, M., Boren, J., and Pilon, M. (2019). AdipoR1 and AdipoR2 maintain membrane fluidity in most human cell types and independently of adiponectin. J Lipid Res 60 , 995-1004.

Rutkowski, D.T., Arnold, S.M., Miller, C.N., Wu, J., Li, J., Gunnison, K.M., Mori, K., Sadighi Akha, A.A., Raden, D., and Kaufman, R.J. (2006). Adaptation to ER stress is mediated by differential stabilities of pro-survival and pro-apoptotic mRNAs and proteins. PLoS Biol 4, e374.

Schneider, C.A., Rasband, W.S., and Eliceiri, K.W. (2012). NIH Image to ImageJ: 25 years of image analysis. Nat Methods 9, 671-675.

Shen, Y., Zhao, Z., Zhang, L., Shi, L., Shahriar, S., Chan, R.B., Di Paolo, G., and Min, W. (2017). Metabolic activity induces membrane phase separation in endoplasmic reticulum. Proc Natl Acad Sci U S A 114, 13394-13399. 
Sulston, J., and Hodgkin, J. (1988). The nematode Caenorhabditis elegan. W.B. Wood, ed. (Cold Spring Harbor Laboratory Press), pp. 507-606.

Svensk, E., Stahlman, M., Andersson, C.H., Johansson, M., Boren, J., and Pilon, M. (2013). PAQR-2 regulates fatty acid desaturation during cold adaptation in C. elegans. PLoS Genet 9 , e1003801.

Svensson, E., Olsen, L., Morck, C., Brackmann, C., Enejder, A., Faergeman, N.J., and Pilon, M. (2011). The adiponectin receptor homologs in C. elegans promote energy utilization and homeostasis. PLoS One 6, e21343.

Tanabe, H., Fujii, Y., Okada-Iwabu, M., Iwabu, M., Nakamura, Y., Hosaka, T., Motoyama, K., Ikeda, M., Wakiyama, M., Terada, T., et al. (2015). Crystal structures of the human adiponectin receptors. Nature 520, 312-316.

Van Gilst, M.R., Hadjivassiliou, H., and Yamamoto, K.R. (2005). A Caenorhabditis elegans nutrient response system partially dependent on nuclear receptor NHR-49. Proc Natl Acad Sci U S A 102, 13496-13501.

Varga, T., Czimmerer, Z., and Nagy, L. (2011). PPARs are a unique set of fatty acid regulated transcription factors controlling both lipid metabolism and inflammation. Biochim Biophys Acta 1812, 1007-1022.

Vasiliauskaite-Brooks, I., Sounier, R., Rochaix, P., Bellot, G., Fortier, M., Hoh, F., De Colibus, L., Bechara, C., Saied, E.M., Arenz, C., et al. (2017). Structural insights into adiponectin receptors suggest ceramidase activity. Nature 544, 120-123.

Walker, A.K., Jacobs, R.L., Watts, J.L., Rottiers, V., Jiang, K., Finnegan, D.M., Shioda, T., Hansen, M., Yang, F., Niebergall, L.J., et al. (2011). A conserved SREBP1/phosphatidylcholine feedback circuit regulates lipogenesis in metazoans. Cell 147, 840-852. Wani, K.A., Goswamy, D., Taubert, S., Ratnappan, R., Ghazi, A., and Irazoqui, J.E. (2021). NHR-49/PPAR-alpha and HLH-30/TFEB cooperate for C. elegans host defense via a flavincontaining monooxygenase. Elife 10 .

Watts, J.L., and Ristow, M. (2017). Lipid and Carbohydrate Metabolism in Caenorhabditis elegans. Genetics 207, 413-446.

Wisniewski, J.R., Zougman, A., Nagaraj, N., and Mann, M. (2009). Universal sample preparation method for proteome analysis. Nat Methods 6, 359-362.

Xu, M., Eblimit, A., Wang, J., Li, J., Wang, F., Zhao, L., Wang, X., Xiao, N., Li, Y., Wong, L.J., et al. (2016). ADIPOR1 Is Mutated in Syndromic Retinitis Pigmentosa. Hum Mutat 37, 246-249.

Yamauchi, T., Kamon, J., Ito, Y., Tsuchida, A., Yokomizo, T., Kita, S., Sugiyama, T., Miyagishi, M., Hara, K., Tsunoda, M., et al. (2003). Cloning of adiponectin receptors that mediate antidiabetic metabolic effects. Nature 423, 762-769.

Yamauchi, T., Nio, Y., Maki, T., Kobayashi, M., Takazawa, T., Iwabu, M., Okada-Iwabu, M., Kawamoto, S., Kubota, N., Kubota, T., et al. (2007). Targeted disruption of AdipoR1 and AdipoR2 causes abrogation of adiponectin binding and metabolic actions. Nat Med 13, 332339.

Zhang, J., Wang, C., Shen, Y., Chen, N., Wang, L., Liang, L., Guo, T., Yin, X., Ma, Z., Zhang, B., et al. (2016). A mutation in ADIPOR1 causes nonsyndromic autosomal dominant retinitis pigmentosa. Hum Genet 135, 1375-1387.

Zhang, L., Orban, M., Lorenz, M., Barocke, V., Braun, D., Urtz, N., Schulz, C., von Bruhl, M.L., Tirniceriu, A., Gaertner, F., et al. (2012). A novel role of sphingosine 1-phosphate receptor S1pr1 in mouse thrombopoiesis. J Exp Med 209, 2165-2181.

Zhu, X.G., Nicholson Puthenveedu, S., Shen, Y., La, K., Ozlu, C., Wang, T., Klompstra, D., Gultekin, Y., Chi, J., Fidelin, J., et al. (2019). CHP1 Regulates Compartmentalized Glycerolipid Synthesis by Activating GPAT4. Mol Cell 74, 45-58 e47. 
bioRxiv preprint doi: https://doi.org/10.1101/2021.08.12.456080; this version posted August 12, 2021. The copyright holder for this preprint

(which was not certified by peer review) is the author/funder, who has granted bioRxiv a license to display the preprint in perpetuity. It is made available under aCC-BY-NC-ND 4.0 International license.

A

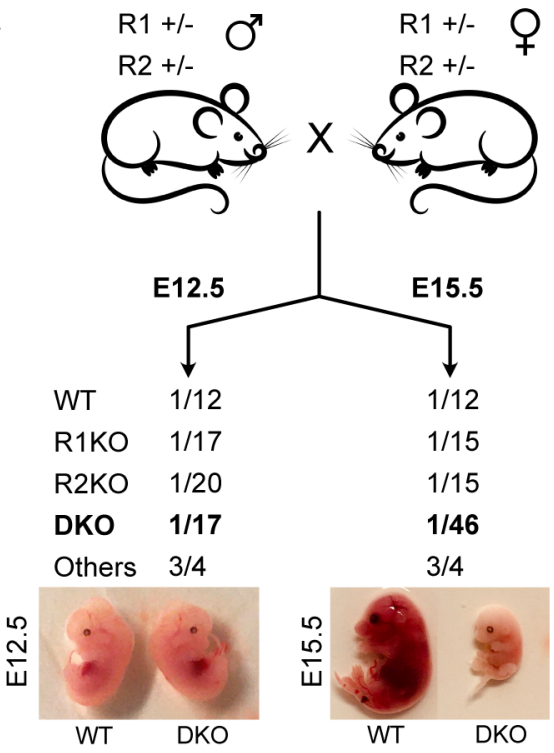

B

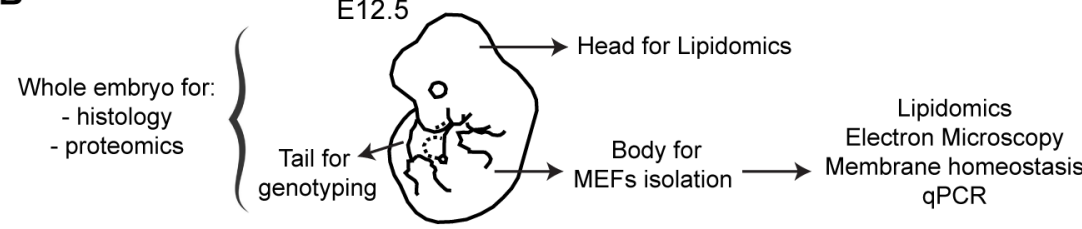

C

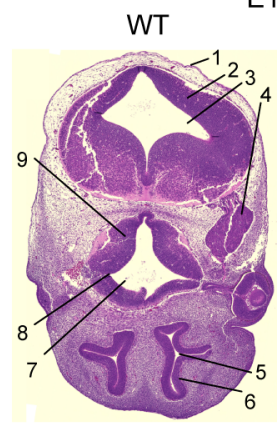

D PCA Lipidomics $(q<0.05)$
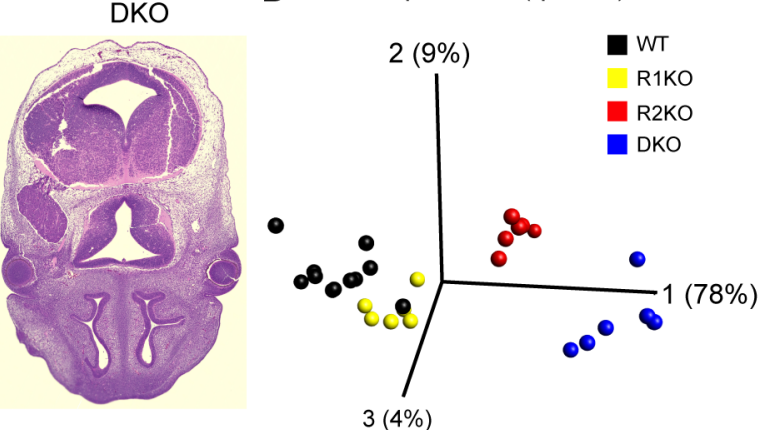

Lipidomics: WT vs DKO

E

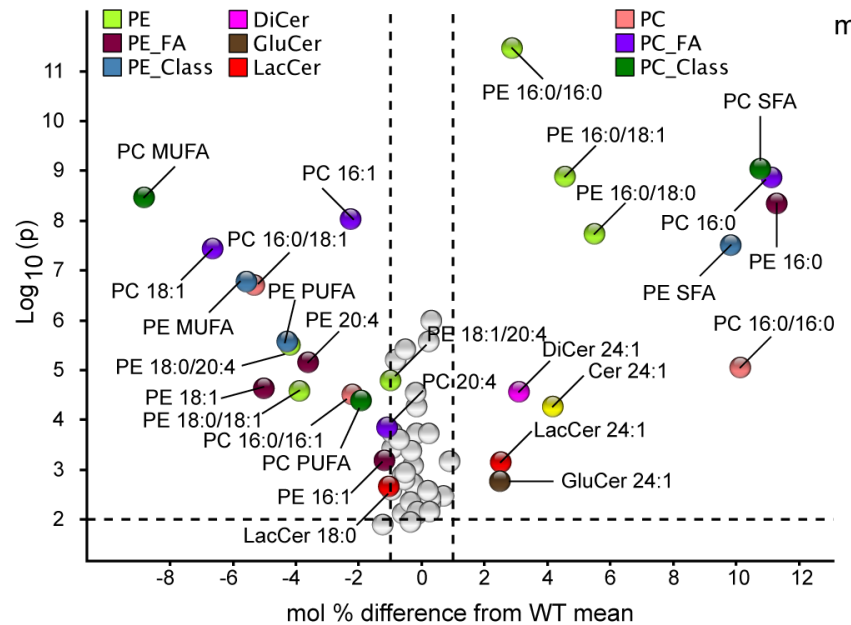

$\mathbf{F}$

FA in various lipids with $q<0.05$
G Proteomics: Identification

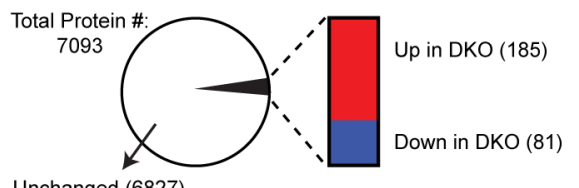

Unchanged (6827)

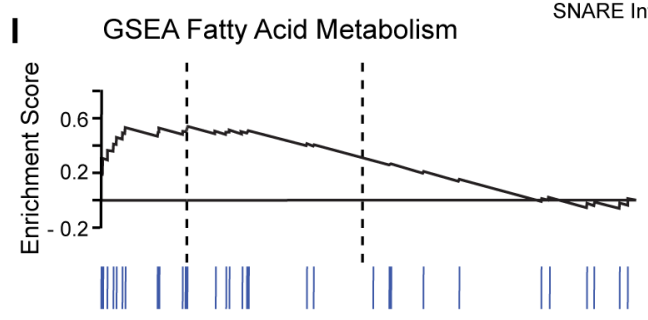

H

GSEA Proteomics $(q<0.05)$

Down in DKO Up in DKO

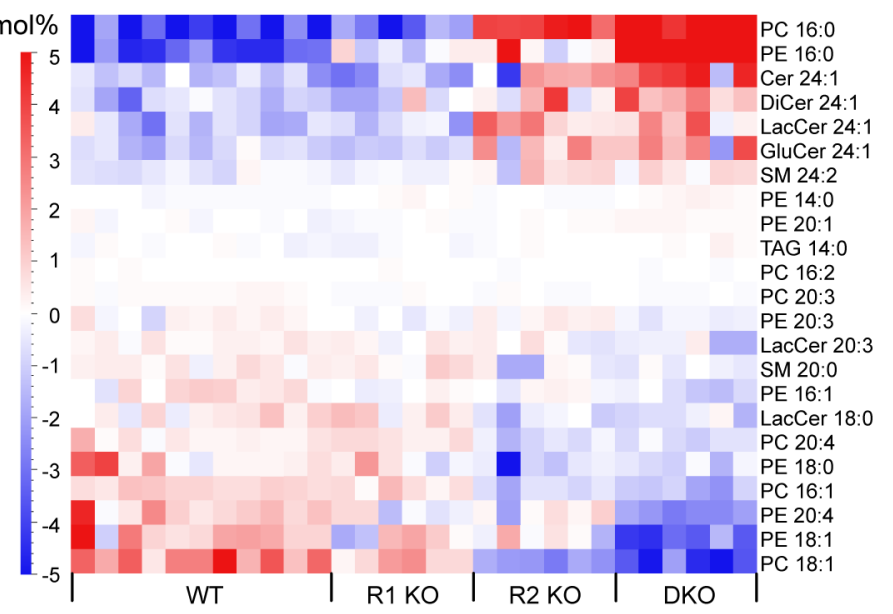

J

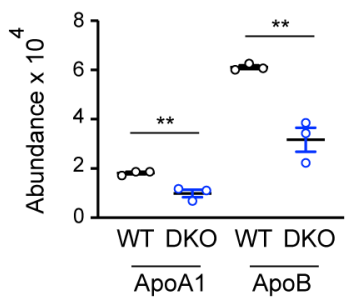

K

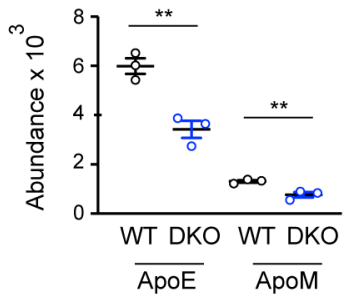




\section{Figure 1. Membrane Lipid Composition Defects Precede Embryonic Lethality in DKO} Mice.

(A) Schematic representation of the mouse crosses, genotypic frequency of mouse embryos obtained at E12.5 $(n=218)$ and E15.5 $(n=46)$ and representative images of the embryos. Note the unexpected low fraction of DKO embryos at E15.5: only 1/46 E15.5 DKO compared with the expected fraction $1 / 16$. See also Table 1 .

(B) Schematic representation of a mouse embryo at E12.5. The body parts used for each experiment are indicated.

(C) Sections of WT and DKO embryos at E12.5 stained with H\&E. No major differences were found between genotypes. 1. surface ectoderm; 2. fourth ventricle; 3. basal plate of metencephalon; 4. trigeminal (V) ganglion; 5. lumen of primitive nasal cavity; 6. olfactory epithelium; 7. third ventricle; 8. optic recess; 9. region of optic chiasma. More sections are shown in Fig.S1B-I.

(D) Lipidomics study of WT, R1KO, R2KO and DKO heads of mouse embryos at E12.5. PCA showing the separation among different phenotypes. Variables analyzed in the PCA; total amount of PE, Cer, DiCer, GlcCer, LacCer, TAG and FC normalized by PC, abundance (mol $\%$ ) of fatty acids species and the type of fatty acid (class: SFA, MUFA, PUFA) in the respective categories mentioned above. Variables accounting for genotype separation are shown in Fig.S1I.

(E) Volcano plot of the lipidomics showing all the significant lipid species between WT and DKO at E12.5. Only the species with a mol \% difference $>$ than $1.5 \%$ from WT mean and with a $\mathrm{p}<0.01$ are colored and labeled.

(F) Heatmap of all the lipid species with a $\mathrm{q}<0.05$ when comparing WT, R1KO, R2KO, DKO embryos at E12.5. Variables considered as in panel D. Note that WT embryos were enriched in PC with 16:1 and PE with 18:1 (both MUFA) whereas DKO had elevated PC with 16:0 and PE with 16:0 (SFA). Box plots of specific lipids are shown in Fig.S1K-U. Related lipidomics are included in Table 2. See also Figure S1 and Table 2.

(G) Schematic representation of the total number of proteins identified in WT and DKO embryos at E12.5 and the number of proteins with altered levels $(\mathrm{p}<0.01)$. See also Table 3.

(H) Gene Set Enrichment Analysis (GSEA) of the embryo proteomics: 16 KEGG pathways are over-represented in DKO embryos at E12.5 with $\mathrm{q}<0.05$ and include 97 proteins. See also figure S1V and Table 3.

(I) GSEA Enrichment plot (score curve) of the KEGG Fatty Acid Metabolism Pathway. Dotted lines indicate the maximum and $50 \%$ of the enrichment score (ES). Blue lines represent the proteins within the functional set (hits).

(J-K) Abundance of several apolipoproteins in WT and DKO embryos at E12.5. Note that all of them are diminished in the DKO embryos.

Data are represented as mean \pm SEM. ${ }^{* *} \mathrm{p}<0.01$. See also Tables $1-3$ 
bioRxiv preprint doi: https://doi.org/10.1101/2021.08.12.456080; this version posted August 12, 2021. The copyright holder for this preprint

(which was not certified by peer review) is the author/funder, who has granted bioRxiv a license to display the preprint in perpetuity. It is made available under aCC-BY-NC-ND 4.0 International license.

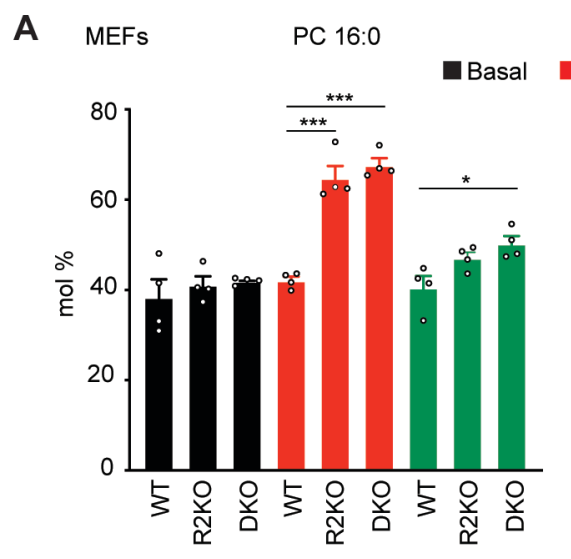

B

-PA $\quad \mathrm{PA}+\mathrm{OA}$

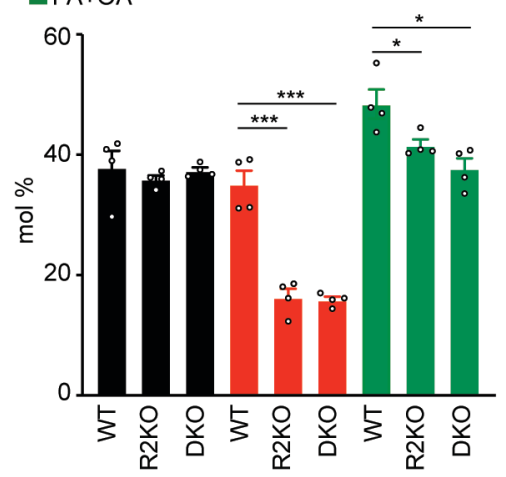

D
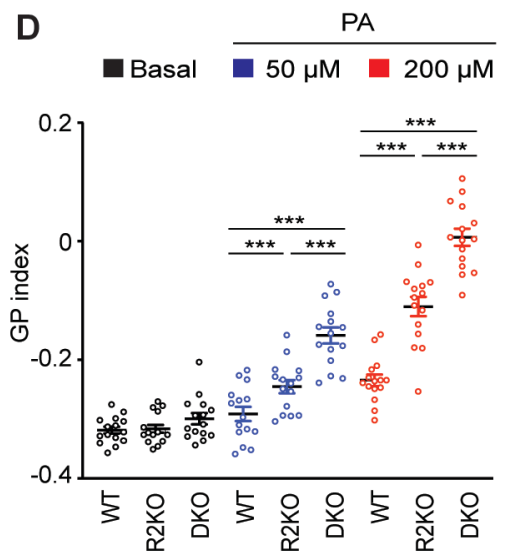

M MEFs

PCA with phospholipids $(q<0.05)$

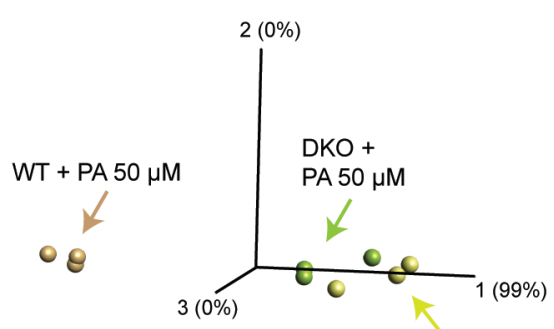

$\mathrm{DKO}+\mathrm{PA} 50 \mu \mathrm{M}+\mathrm{S} 1 \mathrm{P} 1 \mu \mathrm{M}$

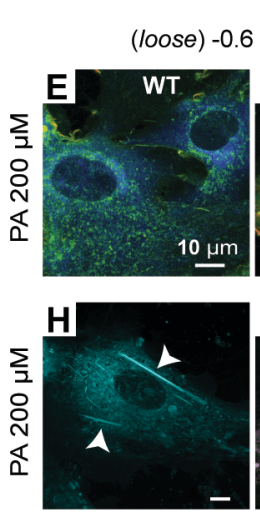

$\mathbf{N}$

PE 16:0
GP index
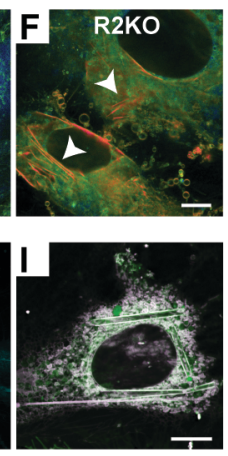

O PE 18:1 PA PA+S1P
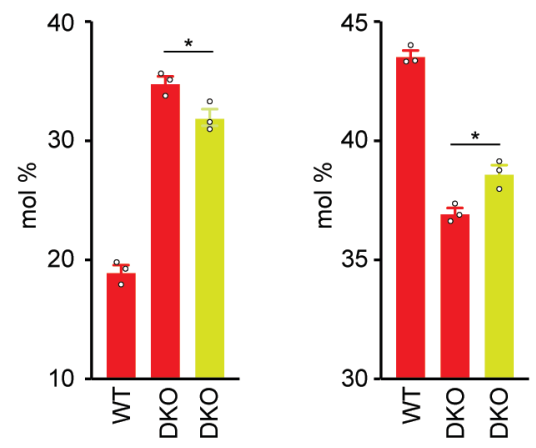

0.62 (packed)
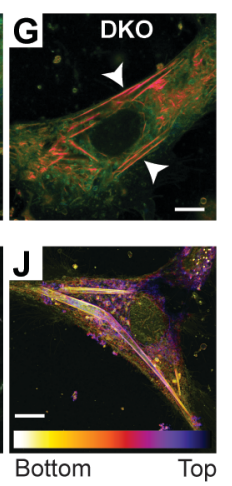

C IPL with SFA IPL with MUFA Laurdan
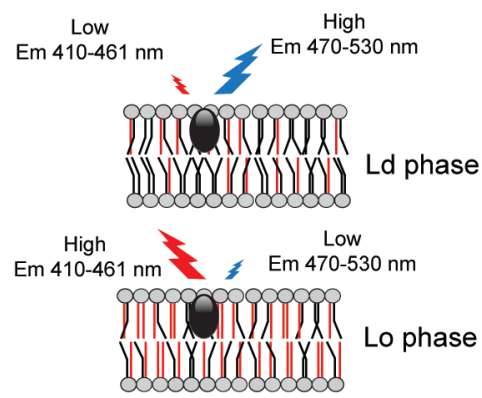

K $\quad$ DKO MEFs + PA $200 \mu \mathrm{M}$

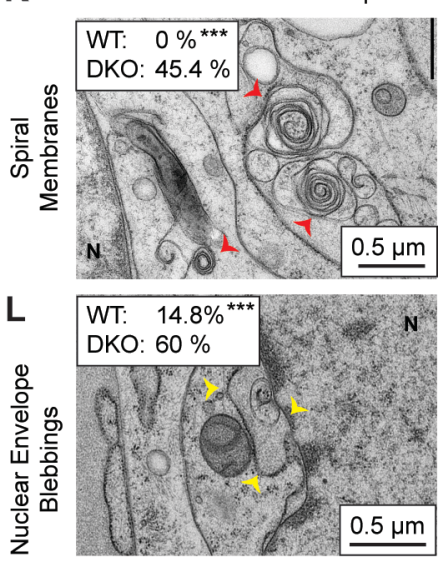

P PE PUFA

Q Laurdan
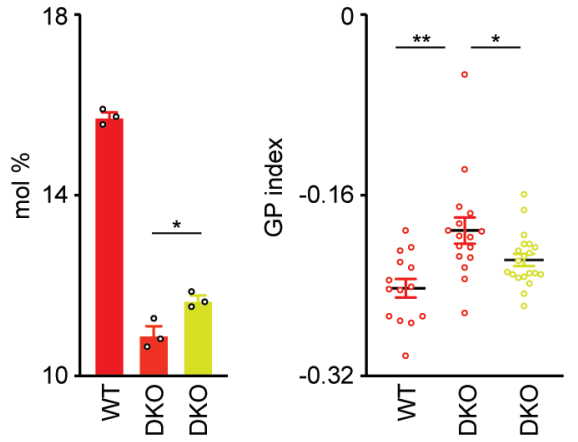

U

V C. elegans

W paqr-2 mutant

$\mathbf{R}$

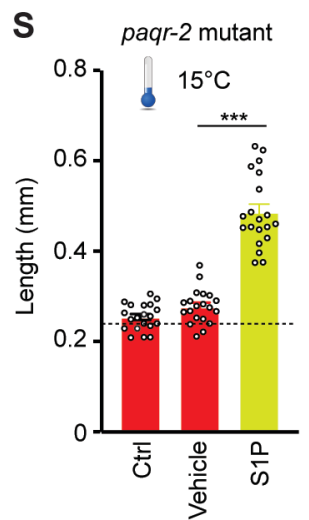

T C. elegans Tail morphology

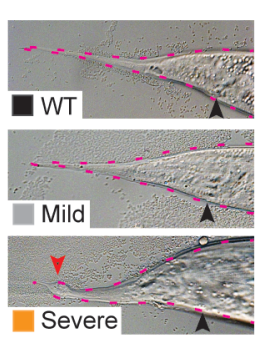

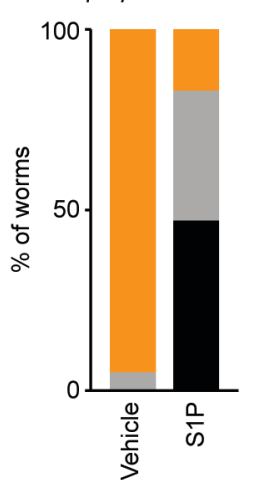

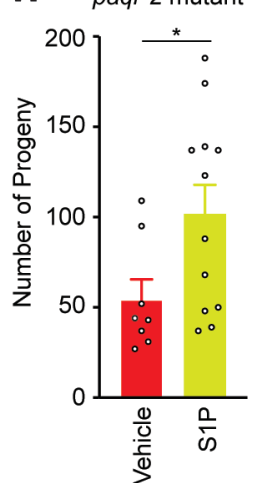




\section{Figure 2. S1P Rescues Membrane Homeostasis Defects Caused by the Absence of} AdipoR2 in MEFs and C. elegans.

(A-B) PA (16:0) and OA (18:1) abundance (mol\%) in the PC of WT, R2KO or DKO MEFs cultivated in the presence of vehicle and PA $200 \mu \mathrm{M} \pm \mathrm{OA} 200 \mu \mathrm{M}$ for $18 \mathrm{~h}$. Related lipidomics are shown in Fig.S2A-C and Table S4.

(C) Schematic representation of the Laurdan dye method used to measure lipid packing.

(D) Average GP index from several images of WT, R2KO and DKO MEFs treated with vehicle, PA $50 \mu \mathrm{M}$ or PA $200 \mu \mathrm{M}$ for $18 \mathrm{~h}$ and stained with Laurdan.

(E-G) Representative pseudocolor images from F showing the Laurdan dye GP index at each pixel position of WT, R2KO and DKO MEFs challenged with PA $200 \mu \mathrm{M}$. Note the pronounced rigidification of $\mathrm{R} 2 \mathrm{KO}$ and $\mathrm{DKO}$ cells showed by red pixels and the presence of long and packed structures (indicated by white arrows). Enlarged examples of WT and DKO MEFs are shown in Fig.S2F.

(H) Confocal image of live R2KO MEFs stained with C1-Bodipy-C12 after PA $200 \mu \mathrm{M}$ treatment. Single channel images are shown in Fig.S2G.

(I) R2KO MEFs challenged with PA $200 \mu \mathrm{M}$ and stained with Laurdan (in green) and ERtracker (in purple): the merged Laurdan and ER-tracker signals are shown in white. Single channel images are shown in Fig.S2R.

(J) Color-coded image of a Z-stack image of live R2KO MEFs exposed to PA $200 \mu \mathrm{M}$ and stained with C1-Bodipy-C12.

(K-L) Electron microscopy images illustrating membrane defects [spiral membranes in K labeled with red arrows (zoom in of Fig.S2J) ( $\mathrm{n}=22-27$ sections) and nuclear envelop blebbing in L labeled with yellow arrows (zoom in of Fig.S2L) ( $n=17-27$ sections with nuclei)] in DKO MEFs treated with PA $200 \mu \mathrm{M}$. N in the pictures indicates the nuclei. Larger images and detailed quantifications are shown in Fig.S2L-M and S2Q-R.

(M) Lipidomic study of WT MEFs treated with PA $50 \mu \mathrm{M}$ and DKO exposed to PA $50 \mu \mathrm{M} \pm$ S1P $1 \mu \mathrm{M}$. PCA calculated with the abundance (mol\%) of fatty acid species in the PC and PE. $\mathrm{q}<0.05$.

(N-P) Abundance of PA (16:0), OA (18:1) and PUFA in PE of WT and DKO MEFs treated with PA $50 \mu \mathrm{M} \pm \mathrm{S} 1 \mathrm{P} 1 \mu \mathrm{M}$. Related lipidomics are shown in Table S4.

(Q). Average GP index from several images of DKO MEFs treated with PA $50 \mu \mathrm{M} \pm \mathrm{S} 1 \mathrm{P} 1$ $\mu \mathrm{M}$ and stained with Laurdan.

(R-S) Representative pictures and quantification of the length of paqr-2 mutant worms grew in control plates and vehicle $\pm \mathrm{S} 1 \mathrm{P} 25 \mu \mathrm{M}$ at $15^{\circ} \mathrm{C}$ for $144 \mathrm{~h}$. Black arrows point to worms. Note that paqr-2 mutant worms arrested as L1 and the treatment with S1P allowed them to reach the L4-adult stage. The dashed line in S represents the approximate length of the L1s at the start of the experiments.

(T-U) Representative images and quantification ( $\mathrm{n}=50$ worms/genotype) of the tail tip morphology of 1-day adult C. elegans: WT phenotype (upper panel) and mild and severe defects (central and lower images respectively). Note that shorter and broader tail tips were scored as mild defect, whereas deformed and bumpy tails were scored as severe defect (indicated by the red arrow). Black arrows point to the anus. 
(V-W) Schematic representation of $C$. elegans. The region of the gonad where S1P was injected is highlighted in orange. Total brood size of paqr-2 mutant injected with vehicle and S1P $10 \mu \mathrm{M}$.

Data are represented as mean \pm SEM. ${ }^{*} \mathrm{p}<0.05,{ }^{* *} \mathrm{p}<0.01,{ }^{* * *} \mathrm{p}<0.001$. See also Figures S2-3 and Table S4. 
bioRxiv preprint doi: https://doi.org/10.1101/2021.08.12.456080; this version posted August 12, 2021. The copyright holder for this preprint

(which was not certified by peer review) is the author/funder, who has granted bioRxiv a license to display the preprint in perpetuity. It is made available under aCC-BY-NC-ND 4.0 International license.

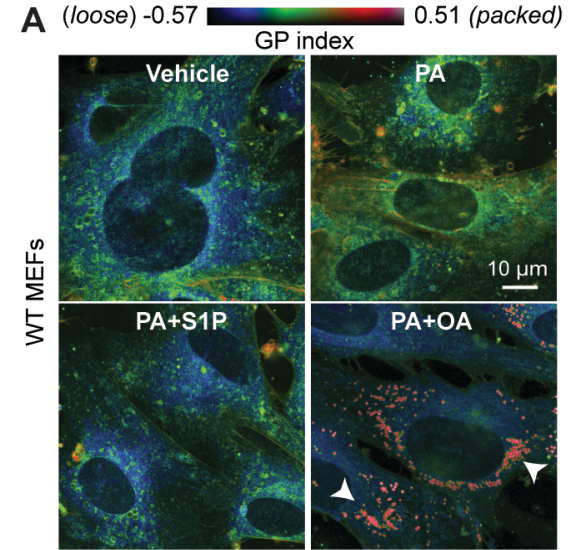

B WT MEFs

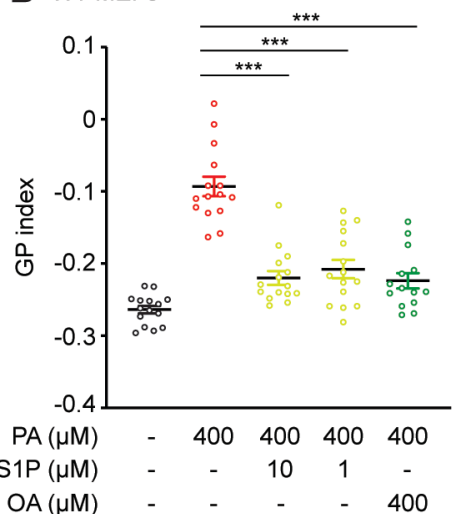

S1P $(\mu \mathrm{M})$
OA $(\mu \mathrm{M})$

$\mathbf{F}$

E INS-1E

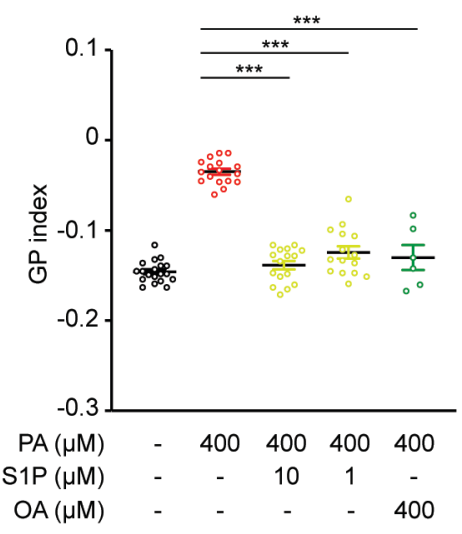

INS-1E

GSIS

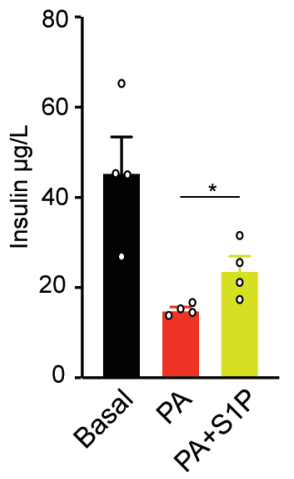

C

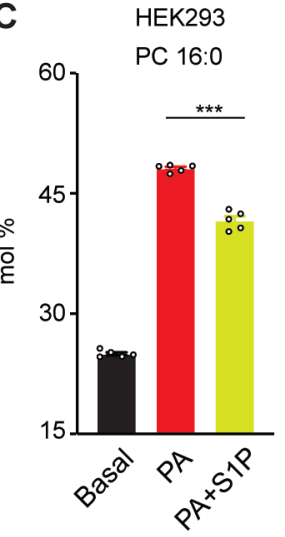

D HEK293

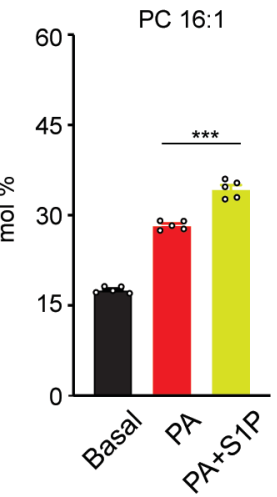

HEK293

Basal पPA

H
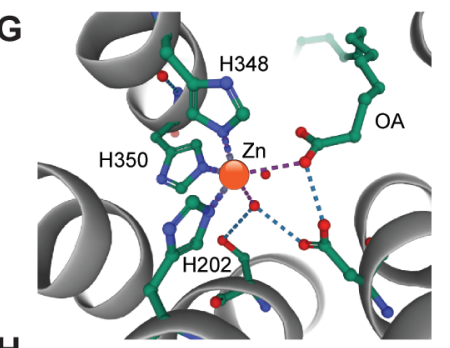

HA

$-55 \mathrm{kD}$

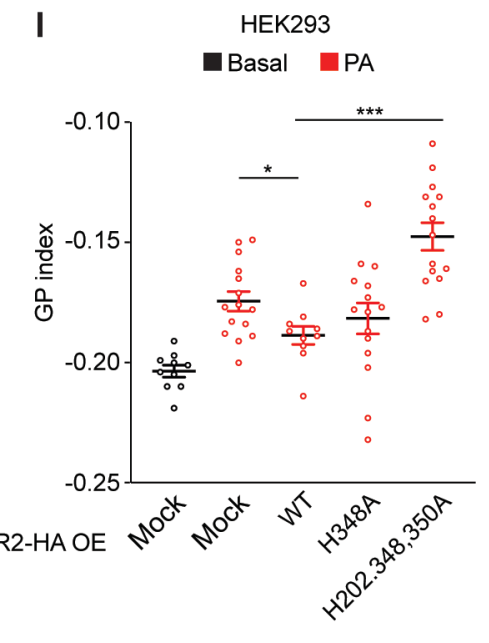


Figure 3. S1P Promotes Resistance Against Saturated Fatty Acids by Improving Membrane Homeostasis in Multiple Human/Rat Cell Types.

(A-B) Pseudocolor images and average GP index from several images of WT MEFs treated with vehicle, $\mathrm{PA} 400 \mu \mathrm{M} \pm \mathrm{S} 1 \mathrm{P} 10$ or $1 \mu \mathrm{M} \pm \mathrm{OA} 400 \mu \mathrm{M}$ for $18 \mathrm{~h}$ and stained with Laurdan. Note the large number of "small" and highly packed lipid droplets induced by PA+OA (indicated by white arrows).

(C-D) PA (16:0) abundance (mol\%) in the PC and PE of HEK293 cells cultivated in the presence of PA $400 \mu \mathrm{M} \pm \mathrm{S} 1 \mathrm{P} 10 \mu \mathrm{M}$ for $24 \mathrm{~h}$. Related lipidomics are shown in Table S5.

(E) Pseudocolor images and average GP index from several images of the rat insulinoma INS$1 \mathrm{E}$ treated with vehicle, PA $400 \mu \mathrm{M} \pm \mathrm{S} 1 \mathrm{P} 10$ or $1 \mu \mathrm{M} \pm \mathrm{OA} 400 \mu \mathrm{M}$ and stained with Laurdan. (F) Glucose stimulated insulin secretion (GSIS) assay: Amount of secreted insulin (for $2 \mathrm{~h}$ ) to the medium by INS-1E cells pre-exposed to vehicle and PA $400 \mu \mathrm{M} \pm \mathrm{S} 1 \mathrm{P}$ for $18 \mathrm{~h}$.

(G) Schematic representation of the $\mathrm{Zn}^{2+}$ atom inside of the structure of human AdipoR2. PDB 5LX9 entry was used as model (Vasiliauskaite-Brooks et al., 2017). Note that the $\mathrm{Zn}^{2+}$ is coordinated by three histidines.

(H) Western-Blot of AdipoR2 and Tubulin in HEK293 cells transfected with human AdipoR2: WT sequence, H348A mutant and H202,348,350A mutations.

(I) Average GP index from several images of HEK293 cells transfected with human AdipoR2: WT sequence, H348A mutant and H202,348,350A mutations and challenged with PA $400 \mu \mathrm{M}$ for $24 \mathrm{~h}$.

Data are represented as mean \pm SEM. ${ }^{*} \mathrm{p}<0.05,{ }^{* *} \mathrm{p}<0.01,{ }^{* * *} \mathrm{p}<0.001$. See also Figure S4 and Tables S5-6. 
bioRxiv preprint doi: https://doi.org/10.1101/2021.08.12.456080; this version posted August 12, 2021. The copyright holder for this preprint

(which was not certified by peer review) is the author/funder, who has granted bioRxiv a license to display the preprint in perpetuity. It is made available under aCC-BY-NC-ND 4.0 International license.

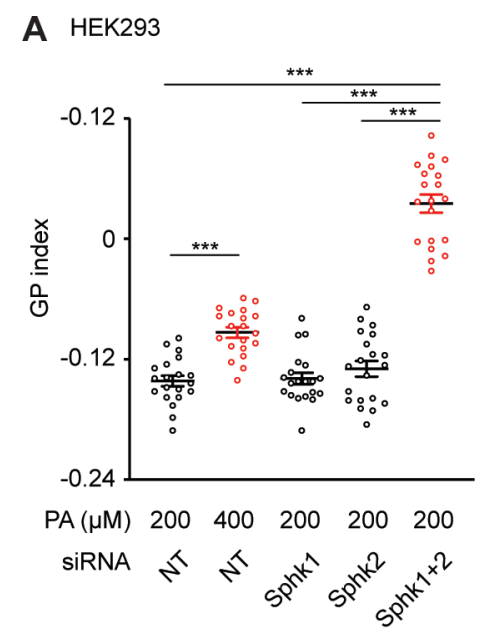

E

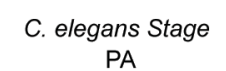

adult L4 LL1-L3

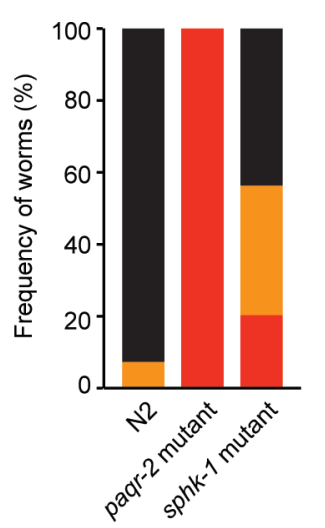

B FRAP in Intestinal

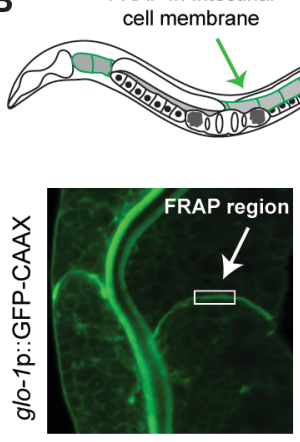

C

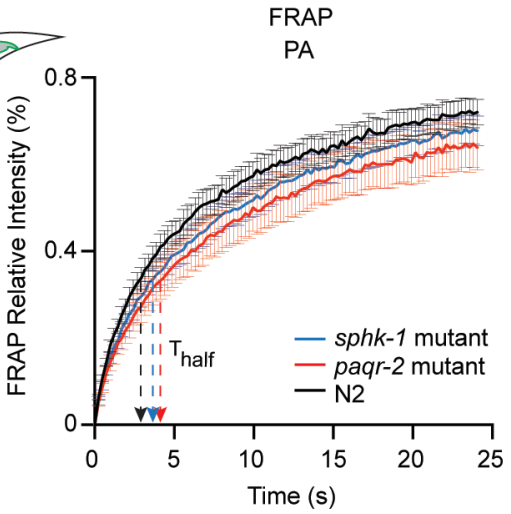

D C. elegans

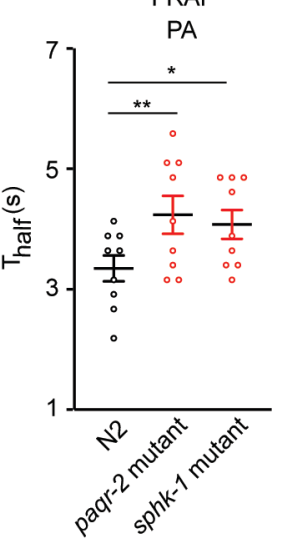

F Tail morphology

PA

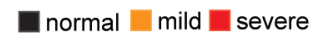

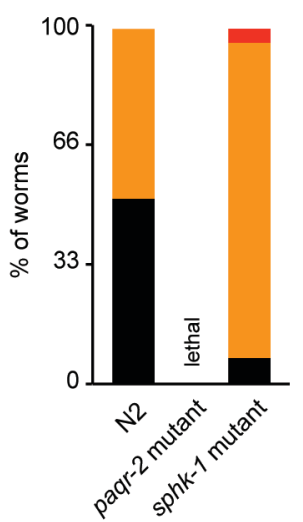

G

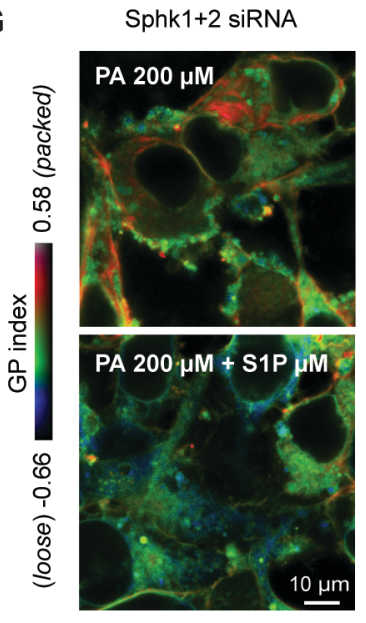

H HEK293

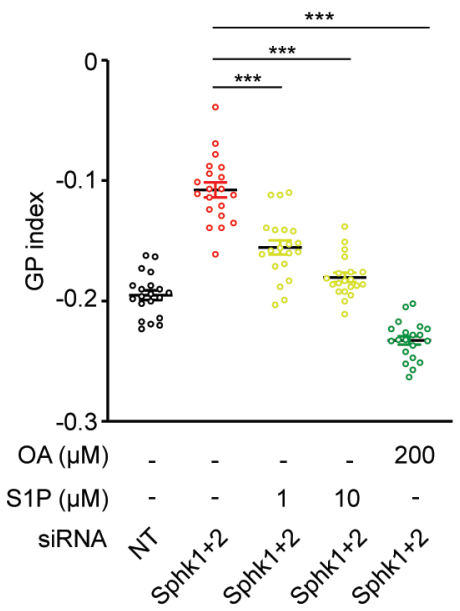


Figure 4. Role of Sphingosine Kinases in Maintaining Membrane Homeostasis in Human Cells and in $C$. elegans.

(A) Average GP index from several images of NT, Sphk1 and Sphk2 siRNA HEK293 cells treated with PA $200 \mu \mathrm{M}$ and stained with the Laurdan dye.

(B) Schematic representation of $C$. elegans (note that the membrane of intestinal cells is decorated in green representing a membrane bound prenylated GFP) and a confocal image of the actual GFP signal in intestinal cells of $C$. elegans showing a clear membrane pattern. The white square represents the FRAP region.

(C-D) Curves showing the normalized fluorescence during a FRAP experiment of N2, paqr-2 and sphk-1 mutants grown in PA $2 \mathrm{mM}$ plates and quantification using $\mathrm{T}_{\text {half }}$ values. Note that $\mathrm{T}_{\text {half }}$ values represent the time spent after the bleach to recover $50 \%$ of the original fluorescence. (E-F) Quantification of C. elegans larval stages and adulthood in N2, paqr-2 and sphk-1 mutants after $72 \mathrm{~h}$ growing at $20^{\circ} \mathrm{C}$ on normal plates in E. Tail tip morphology of 1-day adult worms grown on plates with PA-loaded OP50 bacteria in $\mathrm{F}$ ( $\mathrm{n}=50$ worms/genotype). Examples of the different tail morphologies are shown in Fig.2T.

(G-H) Pseudocolor images and average GP index from several images of NT and Sphk1+2 siRNA HEK293 cells treated with PA $200 \mu \mathrm{M} \pm \mathrm{S} 1 \mathrm{P} 1 \mu \mathrm{M}$ or \pm OA $200 \mu \mathrm{M}$.

Data are represented as mean \pm SEM. ${ }^{*} p<0.05,{ }^{*} p<<0.01,{ }^{* * *} p<0.001$. See also Figure S4P-Q and Table S6. 
bioRxiv preprint doi: https://doi.org/10.1101/2021.08.12.456080; this version posted August 12, 2021. The copyright holder for this preprint

(which was not certified by peer review) is the author/funder, who has granted bioRxiv a license to display the preprint in perpetuity. It is made available under aCC-BY-NC-ND 4.0 International license.
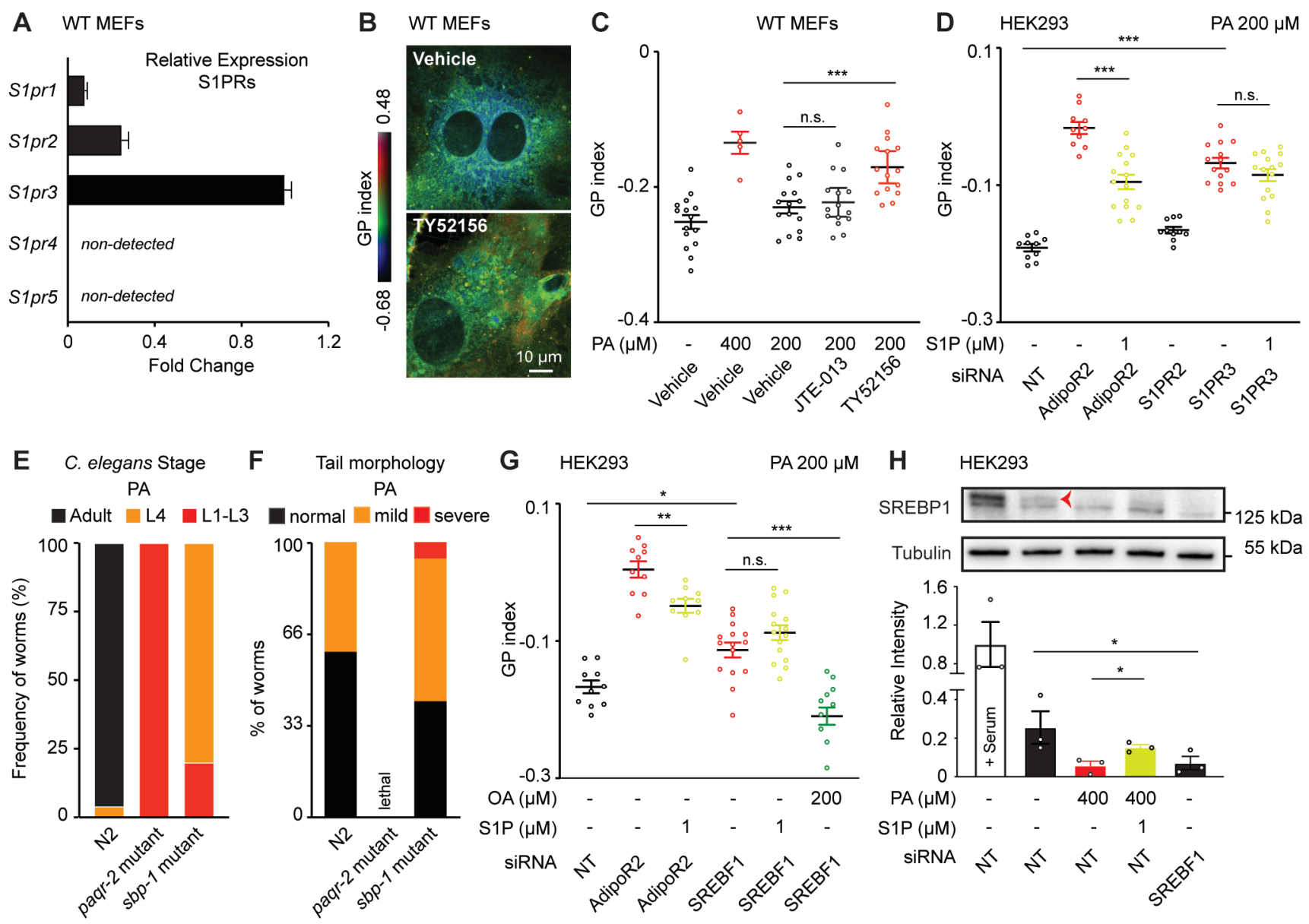

F Tail morpho
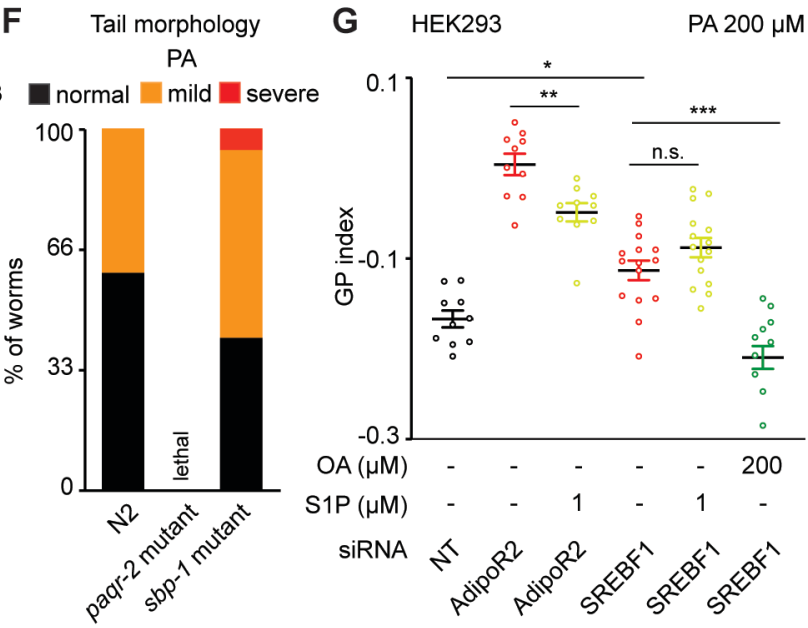

H HEK293
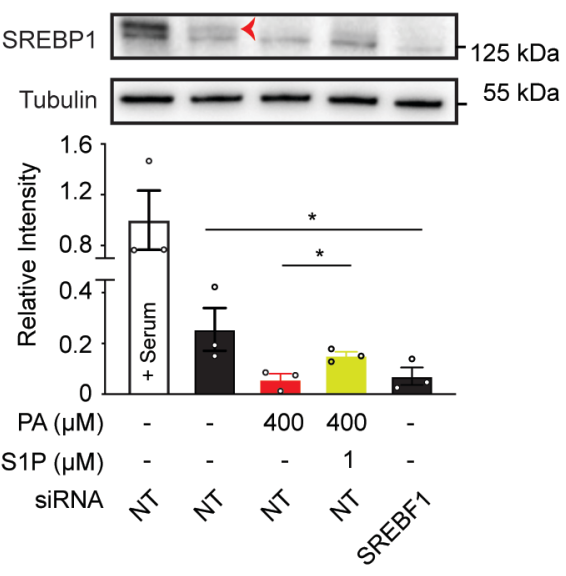
Figure 5. S1P Signaling Via S1PR3 and SREBP1 Maintains Membrane Homeostasis in Human/Mouse Cells and in $C$. elegans.

(A) Relative expression of S1PRs in WT MEFs measured by qPCR.

(B-C) Pseudocolor images and average GP index from several images of WT MEFs treated with vehicle, PA $400 \mu \mathrm{M}$, PA $200 \mu \mathrm{M} \pm$ JTE-013 $5 \mu \mathrm{M}$ (S1PR2 antagonist), \pm TY52156 $5 \mu \mathrm{M}$ (S1PR3 antagonist).

(D) Average GP index from several images of NT, AdipoR2, S1PR2, S1PR3 siRNA HEK293 cells treated with PA $200 \mu \mathrm{M} \pm \mathrm{S} 1 \mathrm{P} 1 \mu \mathrm{M}$.

(E-F) Quantification of C. elegans larval stages and adulthood in N2, paqr-2 and sbp-1 mutants after $72 \mathrm{~h}$ growing at $20^{\circ} \mathrm{C}$ on normal plates in E. Tail tip morphology of 1-day adult worms grown on plates with PA-loaded OP50 bacteria in $\mathrm{F}$ ( $\mathrm{n}=50$ worms/genotype). Examples of the different tail morphologies are shown in Fig.2T.

(G) Average GP index from several images of NT, AdipoR2 and SREBF1 siRNA HEK293 cells treated with PA $200 \mu \mathrm{M} \pm \mathrm{S} 1 \mathrm{P} 1 \mu \mathrm{M}$ and $\pm \mathrm{OA} 200 \mu \mathrm{M}$.

(H) Western-Blot and quantification of NT and SREBF1 siRNA HEK293 cells treated with vehicle and PA $400 \mu \mathrm{M} \pm \mathrm{S} 1 \mathrm{P} 1 \mu \mathrm{M}$. The red arrow points to the precursor SREBP1 band. Note the presence of an unspecific band just below SREBP1 band.

Data are represented as mean \pm SD in A and \pm SEM in C-D and G-H. ${ }^{*} p<0.05, * * p<0.01$, $* * * p<0.001$. See also Figure S5 and Table S6. 
bioRxiv preprint doi: https://doi.org/10.1101/2021.08.12.456080; this version posted August 12,2021 . The copyright holder for this preprint

(which was not certified by peer review) is the author/funder, who has granted bioRxiv a license to display the preprint in perpetuity. It is made available under aCC-BY-NC-ND 4.0 International license.

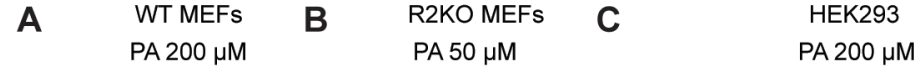

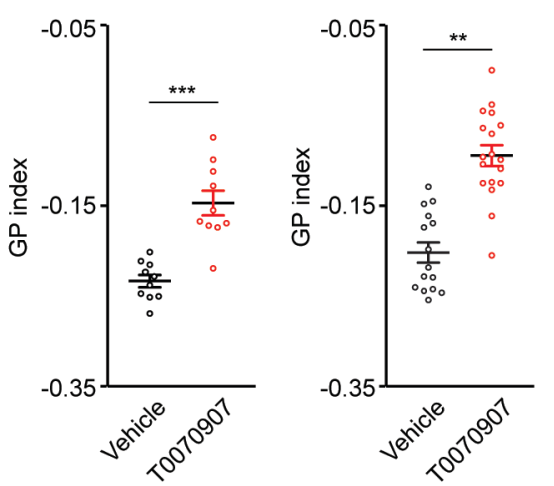

F Tail morphology

anormal $\square$ mild $\square$ severe

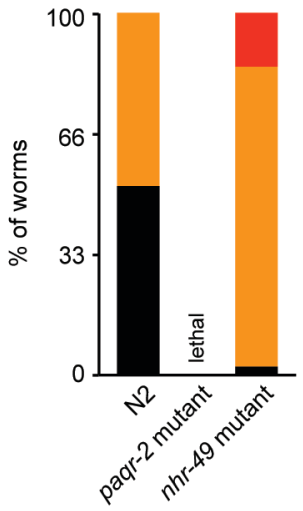

G C. elegans Intestinal nuclei

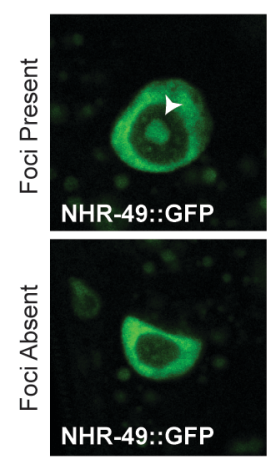

H

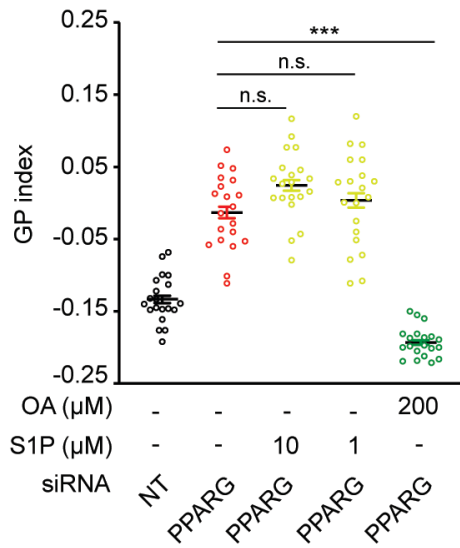

C. elegans
D

C. elegans FRAP

PA

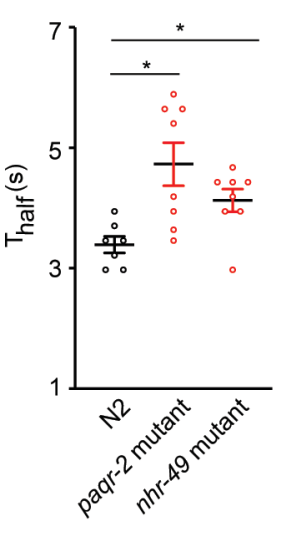

$\mathbf{E}$

adult $\quad$ L4 $\square$ L1-L3

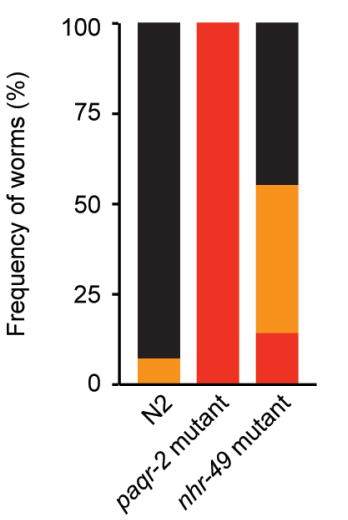

I

N2 paqr-2 mutant paqr-2 mutant + S1P

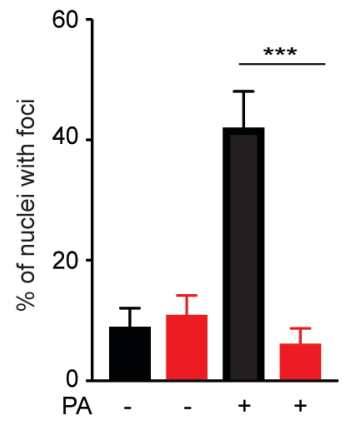

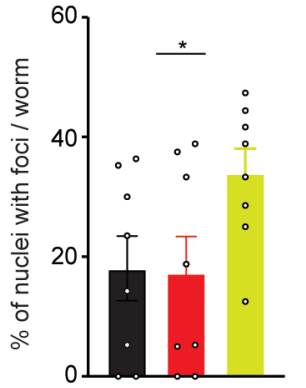

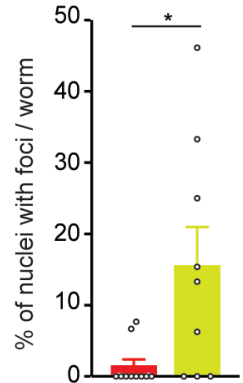




\section{Figure 6. S1P Signaling Via PPAR $\gamma$ Maintains Membrane Homeostasis in Human/Mouse} Cells and in C. elegans.

(A-B) Average GP index from several images of WT and R2KO MEFs treated with vehicle, $\mathrm{PA}(200$ or $50 \mu \mathrm{M}) \pm \mathrm{T} 00709071 \mu \mathrm{M}$ (PPAR $\gamma$ antagonist). Representative images of A are shown in Fig. S6A.

(C) Average GP index from several images of NT and PPARG siRNA HEK293 cells treated with vehicle and PA $200 \mu \mathrm{M} \pm \mathrm{S} 1 \mathrm{P} 10$ or $1 \mu \mathrm{M}$.

(D) FRAP experiment on N2, paqr-2 and $n h r-49$ mutants grown on plates with PA-loaded OP50 bacteria.

(E-F) Quantification of C. elegans larval stages and adulthood in N2, paqr-2 and nhr-49 mutants after $72 \mathrm{~h}$ growing at $20^{\circ} \mathrm{C}$ on normal plates in E. Tail tip morphology of 1-day adult worms grown on plates with PA-loaded OP50 bacteria in $\mathrm{F}$ ( $\mathrm{n}=50$ worms/genotype). Examples of the different tail morphologies are shown in Fig.2T.

(G-J) Representative confocal images of intestinal nuclei of worms expressing NHR-49::GFP and quantification of the presence of foci (indicated by a white arrow) in intestinal nuclei of $\mathrm{N} 2$ and paqr-2 mutants grown on control plates $(\mathrm{H})(\mathrm{n}=248-332$ nuclei/genotype) and in plates supplemented with $\mathrm{S} 1 \mathrm{P}$ at $20^{\circ} \mathrm{C}(\mathrm{I})$ and $15^{\circ} \mathrm{C}(\mathrm{J})$. More images are shown in Fig.S6P-Q.

Data are represented as mean \pm SEM. ${ }^{*} p<0.05,{ }^{* *} p<0.01,{ }^{* * *} p<0.001$. See also Figure S6 and Table S6. 
bioRxiv preprint doi: https://doi.org/10.1101/2021.08.12.456080; this version posted August 12, 2021. The copyright holder for this preprint

(which was not certified by peer review) is the author/funder, who has granted bioRxiv a license to display the preprint in perpetuity. It is made available under aCC-BY-NC-ND 4.0 International license.

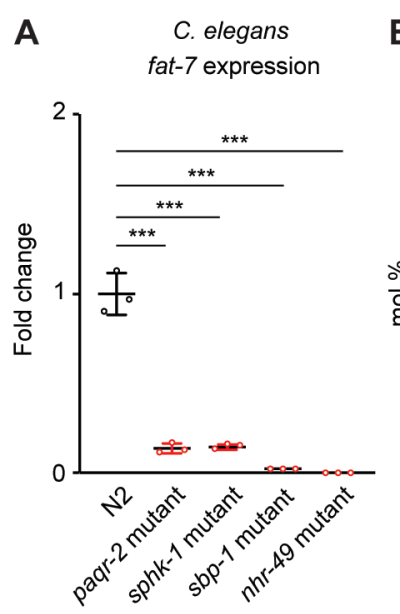

B C. elegans
SFA in PE

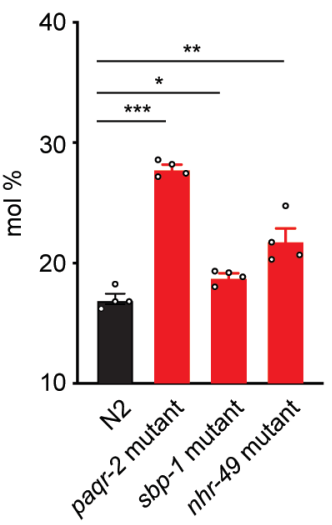

C C. elegans

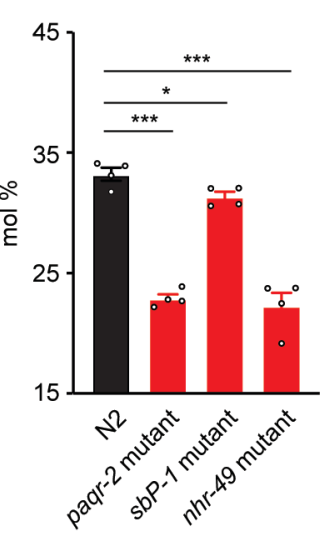

— PA $200 \mu \mathrm{M} \quad$ - PA $200 \mu \mathrm{M}+\mathrm{S} 1 \mathrm{P} 1 \mu \mathrm{M}$

F

F HEK293

PC 16:0

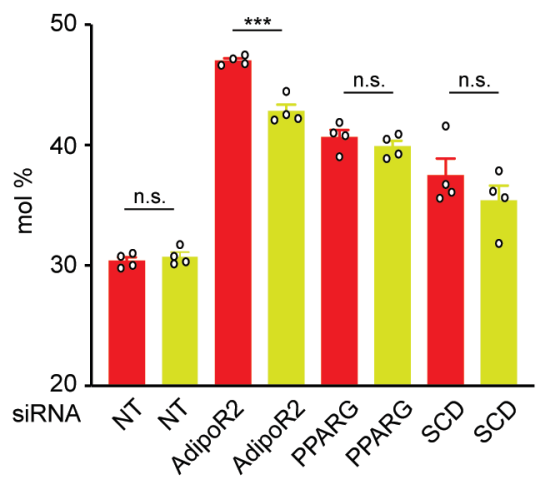

G

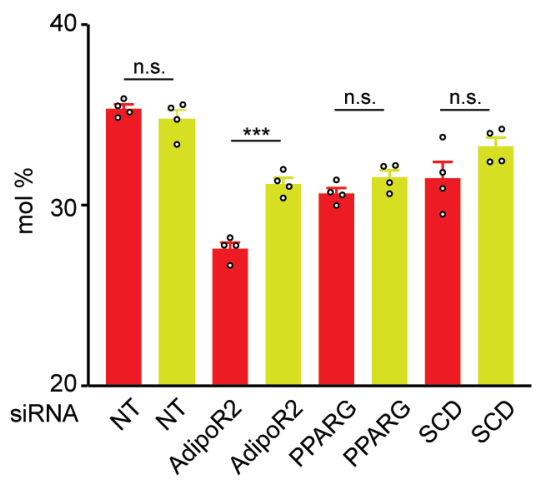

C. elegans

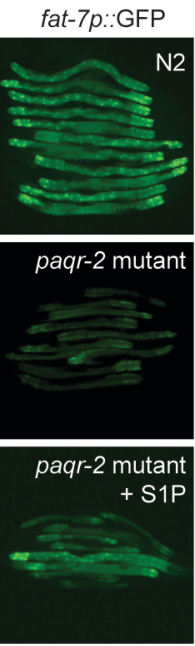

H
E C. elegans fat-7p::GFP

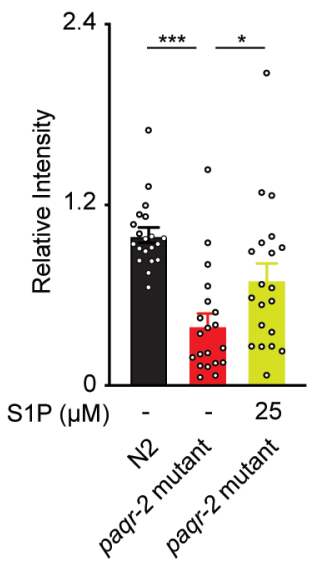

HEK293

PA $200 \mu \mathrm{M}$

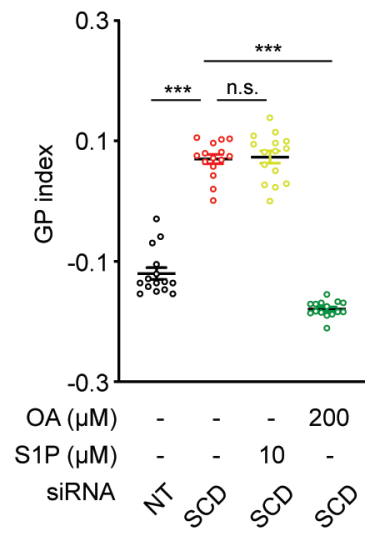


Figure 7. Role of SCD in maintenance of membrane homeostasis in human cells and in $C$. elegans.

(A) Relative expression of fat-7 in N2, paqr-2, sphk1 and $n h r-49$ mutant worms measured by qPCR.

(B-C) PA 16:0) and OA (18:1) abundance (mol\%) and in the PE of C. elegans grown on PA 2 $\mathrm{mM}$ plates. Related lipidomics are shown in Table S7.

(D-E) Representative images $C$. elegans expressing GFP under the control of the fat-7 promoter ( $f a t-7 p:: \mathrm{GFP})$ and the quantification of the fluorescence. $\mathrm{N} 2$ and paqr-2 mutant worms were grown on control plates and plates supplemented with S1P $25 \mu \mathrm{M}$ for $72 \mathrm{~h}$.

(F-G) PA (16:0) and OA (18:1) abundance (mol\%) and in the PC of HEK293 cells treated with vehicle and PA $200 \mu \mathrm{M} \pm \mathrm{S} 1 \mathrm{P} 1 \mu \mathrm{M}$. Related lipidomics are shown in Fig.S7G and in Table S6.

(H) Average GP index from several images of NT and SCD siRNA HEK293 cells treated with vehicle and PA $200 \mu \mathrm{M} \pm \mathrm{S} 1 \mathrm{P} 10 \mu \mathrm{M}$ and \pm OA $200 \mu \mathrm{M}$.

Data are represented as mean \pm SEM. ${ }^{*} p<0.05,{ }^{* *} p<0.01,{ }^{* * *} p<0.001$. See also Figure $\mathrm{S} 7$ Table S5-7. 